\title{
The influence of silicate on transformation pathways of synthetic 2-line ferrihydrite
}

\author{
Grzegorz Rzepa $^{1}$ - Gabriela Pieczara ${ }^{1}$ - Adam Gawel ${ }^{1} \cdot$ Anna Tomczyk $^{1}$ • \\ Ryszard Zalecki ${ }^{2}$
}

Received: 14 August 2015/Accepted: 6 February 2016/Published online: 26 February 2016

(c) The Author(s) 2016. This article is published with open access at Springerlink.com

\begin{abstract}
In this study, a series of synthetic ferrihydrite samples of $\mathrm{Si} / \mathrm{Fe}$ molar ratios ranging from zero to 1.5 were heated up to $1000{ }^{\circ} \mathrm{C}$ using simultaneous TG-DTA equipment. The XRD, FTIR, SEM-EDS and magnetic susceptibility measurements were carried out prior to and after heating. It has been found that silicate retards ferrihydrite transformation to hematite and affects crystallinity of the product. Low $\mathrm{Si}$ admixture in the precursor reduces hematite crystal size severely, but the increase in average crystal dimensions with increasing $\mathrm{Si} / \mathrm{Fe}$ molar ratio was observed. High Si content results in the formation of hematite which exhibits a wide range of crystal habits. The conversion of pure ferrihydrite to hematite proceeds without any intermediate phase, whereas the increasing silicate content in the pristine oxyhydroxide strongly affects the transformation pathway. During annealing of high-Si ferrihydrites, the presence of two or three intermediate $\mathrm{Fe}_{2} \mathrm{O}_{3}$ polymorphs (gamma, epsilon and beta) was demonstrated prior to the crystallization of final $\alpha-\mathrm{Fe}_{2} \mathrm{O}_{3}$. The conditions favoring crystallization of intermediate phases result from progressive silica polymerization which forms separate
\end{abstract}

Electronic supplementary material The online version of this article (doi:10.1007/s10973-016-5345-6) contains supplementary material, which is available to authorized users.

Grzegorz Rzepa

gprzepa@cyf-kr.edu.pl

1 Department of Mineralogy, Petrography and Geochemistry, Faculty of Geology, Geophysics and Environmental Protection, AGH University of Science and Technology, al. A. Mickiewicza 30, 30-059 Krakow, Poland

2 Department of Solid State Physics, Faculty of Physics and Applied Computer Science, AGH University of Science and Technology, al. A. Mickiewicza 30, 30-059 Krakow, Poland matrix-type phase and impedes the aggregation of iron oxide nanoparticles.

Keywords Si-ferrihydrite $\cdot$ Hematite $\cdot \varepsilon-\mathrm{Fe}_{2} \mathrm{O}_{3}$. $\beta-\mathrm{Fe}_{2} \mathrm{O}_{3} \cdot$ Maghemite $\cdot$ Thermal transformations

\section{Introduction}

Ferrihydrite $\left(\mathrm{Fe}_{5} \mathrm{HO}_{8} \cdot 4 \mathrm{H}_{2} \mathrm{O}\right)$ is a reddish-brown, poorly ordered iron oxyhydroxide, with variable and non-stoichiometric composition [1-3 and references therein]. The structure and properties of this nanomineral are still under debate [e.g., 4-12]. Currently two models of ferrihydrite structure compete. According to the classic multiphase model, Fe is exclusively octahedrally coordinated [9, 13], while in the second, so-called akdalite model, $20 \%$ of iron atoms are coordinated tetrahedrally $[4,5]$. Irrespective of the model, the number of broad peaks in the XRD pattern gives the descriptive names for the ferrihydrite varieties, with 2-line and 6-line ferrihydrite being the most common. Because of its low crystallinity, high surface area and surface reactivity, ferrihydrite plays significant role in, for example, inorganic weathering processes, biogeochemical cycling of iron and as a scavenger of trace metals and metalloids in various near-surface environments [1-3]. For this reason, substantial amounts of admixtures are present in ferrihydrite chemical composition. In nature, the most common and well-documented impurities include silicate, phosphate, arsenate, sulfate, calcium, aluminum and organic compounds [e.g., 1-3, 14-16]. These ions affect ferrihydrite composition, surface chemistry, reactivity and sorption properties [14, 17-22]. Silicate, the most important impurity, lowers crystallinity of this nanomineral and modifies its morphology, magnetic ordering and solubility 
[15, 23-39], though the ferrihydrite structure itself is not directly altered [30]. Reducing crystallinity has been thought to result from the formation of soluble $\mathrm{Fe}-\mathrm{Si}$ complexes during the oxyhydroxide precipitation. Such complexes delay the nucleation and growth of ferrihydrite crystallites [31]. It is also likely that surface adsorption of silicic acid occurs soon after ferrihydrite nucleation thus impeding crystal growth [30]. A decrease in both ferrihydrite particle size and crystallinity with increasing content of Si was found [17]. The opposite observation [27] suggested that enhanced adsorption of silicate ions to the ferrihydrite surface caused the increase in the nanoparticle dimensions. These ambiguous results might result from the character of the observed objects-Cismasu et al. [17] noted the decrease in individual ferrihydrite particle sizes, but the oxyhydroxide aggregates appeared more compact. Hence, Seehra et al. [27] might observe ferrihydrite aggregates rather than single crystallites. The character of silica association with ferrihydrite depends on $\mathrm{Si} / \mathrm{Fe}$ molar ratio-at low values, monomeric silicate is adsorbed on the ferrihydrite surface, whereas the high ratio promotes polymerizing of silica to form a separate phase [19]. Therefore, at high $\mathrm{Si}$ contents, ferrihydrite particles are probably embedded in a siliceous matrix containing variable amounts of Fe [17]. A slight increase in specific surface areas of low-Si ferrihydrites in comparison with pure oxyhydroxide was also reported [26, 32], but high-Si ferrihydrites exhibited lower surface areas [22]. It may be explained by the increasing oxyhydroxide aggregation and the enhanced compactness of the aggregates, which permitted the penetration of nitrogen molecules during BET measurements.

Ferrihydrite is a metastable phase and a precursor of many iron oxides and oxyhydroxides. Usually, it transforms with time into stable minerals: goethite $(\alpha-\mathrm{FeOOH})$ and/or hematite $\left(\alpha-\mathrm{Fe}_{2} \mathrm{O}_{3}\right)$, through dissolution-reprecipitation and dehydration-rearrangement mechanisms, respectively [1-3]. At elevated temperatures, ferrihydrite converts into hematite but, despite many studies, the details of the process are still controversial and seem to depend on many factors $[5,33]$. When pure oxyhydroxide is annealed, the conversion to $\alpha-\mathrm{Fe}_{2} \mathrm{O}_{3}$ appears to proceed without any intermediates [2], but ligands adsorbed on the ferrihydrite surface complicate the transformation pathway and intermediate hydromaghemite or ferrimagnetic ferrihydrite forms [5, 33, 34]. The transformation of ferrihydrite to hematite is reflected by the sharp exotherm visible on DTA (or DSC) curves at approximately $300-350{ }^{\circ} \mathrm{C}$, though the exact position of the peak depends on both the experimental conditions and the method of synthesis. In some cases, two [1, 35] or even three exotherms were recorded [36]. Three different thermal patterns of ferrihydrites, obtained by three different procedures, were argued to reflect various proportions of so-called f-phase in the standard multiphase structural ferrihydrite model [37].

The association of $\mathrm{Si}$ with ferrihydrite surface hindered thermal transformation to hematite [16, 38-41]. This is an effect of the formation of $\mathrm{Fe}-\mathrm{O}-\mathrm{Si}$ layer, blocking the crystal growth sites [38]. These bonds must be broken prior to the formation of hematite [24]. In the most comprehensive study on Si-ferrihydrite thermal transformations [40], the presence of $\mathrm{Si}$ raised the temperature of ferrihydrite transformation up to $740{ }^{\circ} \mathrm{C}$, at $\mathrm{Si} /(\mathrm{Si}+\mathrm{Fe})$ molar ratio of 0.27 . A clear reduction of hematite MCLs along both $c$ and $a$ axes was also observed when low-Si ferrihydrites were annealed, whereas heating of higher-Si ferrihydrites resulted in less developed reduction of the hematite dimensions. These authors concluded that some silica could be incorporated in the hematite during heating of low-Si ferrihydrites to $800{ }^{\circ} \mathrm{C}$, and the $\mathrm{Si}$ caused deformation of hematite structure. At higher temperature, the $\mathrm{Si}$ was ejected from the structure [40]. Besides hematite, amorphous silica, which recrystallizes to cristobalite at higher temperature, has been often reported as a product of annealing of Si-ferrihydrite-rich materials [e.g., 16, 42, 43].

The aim of this work was to determine the influence of $\mathrm{Si}$ admixture in ferrihydrite on its thermal transformation processes and the properties of the products. These issues are important for the understanding of Si-ferrihydrite stability in past and present geochemical systems. Although Si-ferrihydrite was synthesized in many studies [e.g., 18, 39, 40], relatively little is known about its properties and even less about the properties of its transformation products [40]. Also, synthetic ferrihydrites analyzed so far exhibited usually low $\mathrm{Si} / \mathrm{Fe}$ molar ratios, and the data for higher $\mathrm{Si} / \mathrm{Fe}$ ratios are scarce [44]. The reason for this is probably a quite low silica content (up to several mass percent) in most of natural ferrihydrites [1, 25, 45-48], but in some environments, such as modern seafloor hydrothermal vents, higher $\mathrm{Si} / \mathrm{Fe}$ ratios (up to ca. 3) were reported $[15,16,49,50]$. In our study, a much wider range of ferrihydrite $\mathrm{Si} / \mathrm{Fe}$ molar ratios was applied; therefore, the results fill the gap in the knowledge of the geologically important silica-rich ferruginous materials. Moreover, we present here the evidence on more complex transformation routes of heated high-Si ferrihydrites in comparison with low-Si ferrihydrites, because prior to the hematite crystallization, epsilon and beta $\mathrm{Fe}_{2} \mathrm{O}_{3}$ polymorphs were encountered. These exclusively synthetic iron oxides $[2,51]$ are attractive (nano)materials for a wide range of applications [51, 52]. This particularly applies to $\varepsilon-\mathrm{Fe}_{2} \mathrm{O}_{3}$, which exhibits a giant room-temperature coercive field and the ability to absorb electromagnetic waves in gigahertz region. Due to a number of intermediate features, $\varepsilon-\mathrm{Fe}_{2} \mathrm{O}_{3}$ is a structural intermediate between maghemite and hematite, stable in a narrow temperature range, and the 
thermally induced structural transformation of $\gamma-\mathrm{Fe}_{2} \mathrm{O}_{3}$ nanoparticles to hematite is the best known process of $\varepsilon$ $\mathrm{Fe}_{2} \mathrm{O}_{3}$ preparation $[51,52]$. Although $\varepsilon-\mathrm{Fe}_{2} \mathrm{O}_{3}$ was identified previously as a transient product of Si-ferrihydrite annealing [40], neither any explanation of its formation nor further comment or discussion was provided. The cubic $\beta-\mathrm{Fe}_{2} \mathrm{O}_{3}$ has been obtained by a wide range of techniques $[51,53]$, but has not been encountered during heating of ferrihydrite so far. Hence, annealing of high-Si ferrihydrite is a new way of preparation of these rare iron oxides and is here demonstrated to provide four $\mathrm{Fe}_{2} \mathrm{O}_{3}$ polymorphs, which previously was limited solely to ferric sulfate as a precursor.

\section{Experimental}

\section{Sample preparation}

A series of 2-line ferrihydrite samples with different $\mathrm{Si} / \mathrm{Fe}$ molar ratios of $0.00,0.05,0.10,0.20,0.50,0.75,1.00$ and 1.50 (referred below as FHYD-000, FHYD-005, FHYD010 and so on), was obtained by reaction of $\mathrm{Fe}_{2}\left(\mathrm{SO}_{4}\right)_{3}$ with $\mathrm{NaOH}$ in the presence of $\mathrm{Na}_{2} \mathrm{SiO}_{3}$ at $\mathrm{pH} 8.2$ [18, 23]. After $12 \mathrm{~h}$ of stirring, the samples were incubated for $96 \mathrm{~h}$ in room temperature and then dialyzed to remove excess of salts $\left(\mathrm{SO}_{4}^{2-}\right.$ and $\left.\mathrm{Na}^{+}\right)$, which was checked by measurements of the suspension electrolytic conductivity. Finally, the precipitates were freeze-dried using Christ Alpha 1-2 LD apparatus. In order to avoid contamination of the samples by silica from glass, polyethylene vessels were used for preparation of the reagents and for the synthesis experiments. All the reagents involved in the synthesis, supplied by Avantor Performance Materials Poland, were of analytical grade.

\section{Methods of sample characterization}

The precipitates were characterized using X-ray powder diffraction (XRD), infrared Fourier transform spectroscopy (FTIR) and scanning electron microscopy (SEM). Then simultaneous thermal analyses (STA-DTA/TG) were performed. After heating to $1000{ }^{\circ} \mathrm{C}$, all samples were evaluated using XRD, FTIR and SEM-EDS. Additionally, ferrihydrite samples were heated, using the same STA equipment, to various temperatures selected on the basis of the analysis of their thermal patterns. For this purpose, heating was terminated immediately after reaching the desired temperature and the sample was removed and cooled in air. The samples attained temperatures below $100{ }^{\circ} \mathrm{C}$ in $1-3 \mathrm{~min}$, depending on the temperature to which they were annealed.
X-ray diffraction patterns were collected using Rigaku SmartLab instrument equipped with a graphite monochromator, rotation $\mathrm{Cu}$ anode, $45 \mathrm{kV}$ and $200 \mathrm{~mA}$ generator settings, $2^{\circ}-75^{\circ} 2 \Theta$ recording range, $0.05^{\circ}$ step size and counting time of $1 \mathrm{~s}$ per step. Eliminating an influence of instrumental parameters on peak intensities was achieved by adjusting the primary beam value using plano-parallel plate cut from the highly crystalline quartz specimen prior to each analysis. The XRD patterns were evaluated by XRAYAN software using a diffraction pattern database of International Centre for Diffraction Data.

Scanning electron microscope analyses were carried out in low-vacuum mode, using a FEI 200 Quanta FEG microscope equipped with an EDS/EDAX spectrometer. The acceleration voltage was $15-20 \mathrm{kV}$ and the pressure $60 \mathrm{~Pa}$. The samples were not coated with conductive layer.

Thermogravimetric (TG) and differential thermal analysis (DTA) measurements were performed applying Netzsch STA 449F3 Jupiter apparatus. A sample mass of ca. $50 \mathrm{mg}$ was placed in an alumina crucible and heated from 20 to $1000{ }^{\circ} \mathrm{C}$, at $10^{\circ} \mathrm{C} \mathrm{min}^{-1}$ in flowing (synthetic) air $\left(40 \mathrm{~mL} \min ^{-1}\right)$. A preheated sample was used as inert material. Simultaneous analyses of the evolved gases were carried out using quadrupole mass spectrometer-Netzsch QMS 403C Aëolos. The thermal patterns were collected and processed using the Netzsch Proteus Thermal Analysis software. Five reference substances: indium, tin, bismuth, aluminum and gold were used for temperature calibration. The errors of DTA and TG measurements, estimated on the basis of repeated measurements of pure ferrihydrite, are $<1{ }^{\circ} \mathrm{C}$ and $<1$ mass $\%$, respectively.

Infrared spectra were collected using Bruker Sensor 27 spectrometer in the range $400-4000 \mathrm{~cm}^{-1}$. The spectra reported are the resultant of 64 scans at the resolution of $1 \mathrm{~cm}^{-1}$. Prior to analysis, $\mathrm{KBr}$ pellets were obtained by homogenizing $200 \mathrm{mg}$ of ground $\mathrm{KBr}$ with $4 \mathrm{mg}$ of the sample.

The magnetic susceptibility at the liquid nitrogen $(77 \mathrm{~K})$ and room temperature (RT) were measured in the magnetic field amplitude of 4.4 and 0.45 Oe, respectively, using a standard mutual inductance bridge operating at the frequency of $18.9 \mathrm{~Hz}$. A Stanford SR 830 lock-in nanovoltmeter served both as a source for the $A C$ current for the coil, which produced the $A C$ magnetic field, and as a voltmeter of the bridge. The temperature was monitored by the Lake Shore temperature controller employing a chromel-gold $-0.07 \% \mathrm{Fe}$ thermocouple with an accuracy of $\pm 0.05 \mathrm{~K}$ for this experimental setup. Voltage measurement error was $0.1 \mu \mathrm{V}$ at $77 \mathrm{~K}$ and $0.2 \mu \mathrm{V}$ at RT, which translates into the error in magnetic susceptibility estimates of $1-2 \times 10^{-8} \mathrm{~m}^{3} \mathrm{~kg}^{-1}$ and $2-4 \times 10^{-7} \mathrm{~m}^{3} \mathrm{~kg}^{-1}$, respectively, depending on the sample mass. 


\section{Results and discussion}

\section{Properties of the initial ferrihydrites}

For the discussion purposes, the samples were divided into three groups: pure ferrihydrite (PFh), low-Si ferrihydrites (LSFh; samples FHYD-005, FHYD-010 and FHYD-020) and high-Si ferrihydrites (HSFh, samples FHYD-050, FHYD-075, FHYD-100 and FHYD-150). A boundary between the groups of Si-ferrihydrites is $0.2 \mathrm{Si} / \mathrm{Fe}$ molar ratio, which is equal to the number of ferrihydrite adsorption sites, estimated to be $0.2 \mathrm{~mol} \mathrm{~mol}^{-1} \mathrm{Fe}$ [19].

\section{SEM, XRD and FTIR studies}

Electron microscopic observations show cryptocrystalline homogenous materials obtained in all the syntheses [22]. Multiple EDS analyses of the ferrihydrites reveal that the actual $\mathrm{Si} / \mathrm{Fe}$ molar ratios are close to those which were planned. Some sulfur impurities have been detected in FHYD-000 and FHYD-005 samples, while the HSFh exhibits sodium admixtures, increasing with increasing $\mathrm{Si}$ content.

XRD pattern of $\mathrm{PFh}$ is characterized by two broad bands at $d \sim 2.5$ and $1.50 \AA$, typical for the oxyhydroxide $[1,2]$. Increasing silicon content results in a gradual broadening and a shift of the former toward lower two-theta angles. Similar features, observed for both synthetic [17, 18, 27] and natural [16, 41, 49] Si-ferrihydrites, indicate reducing crystallinity and/or lowering crystal size.

Ferrihydrite gives broad infrared absorption maxima at ca. 445 and $590 \mathrm{~cm}^{-1}$ (all the FTIR spectra are attached in supplementary file), resulting from the stretching $\mathrm{Fe}-\mathrm{O}$ vibrations, and a shoulder at ca. $680-690 \mathrm{~cm}^{-1}$ [2]. The position and intensity of the band at $445 \mathrm{~cm}^{-1}$ remains roughly the same for all the samples, while the intensity of the $590 \mathrm{~cm}^{-1}$ band is gradually lowered with the increasing silica content, and in the HSFh spectra, the band is not recognizable. Intensive bands at ca. 3400 and $1635 \mathrm{~cm}^{-1}$ are assigned to the stretching and bending $\mathrm{OH}$ vibrations of the lattice and adsorbed water, respectively $[16,54,55]$. A slight shift of the former to higher wave numbers (up to ca. $3425 \mathrm{~cm}^{-1}$ ) for the highest-Si materials indicates some reduction in bond strength [56]. For all the samples containing $\mathrm{Si}$, an additional band attributable to $\mathrm{Si}-\mathrm{O}-\mathrm{Fe}$ stretching $[16,25,41]$ occurs. Its shift from 930 up to $1000 \mathrm{~cm}^{-1}$ with increasing $\mathrm{Si} / \mathrm{Fe}$ molar ratio indicates partial silicate polymerization $[25,46]$. Similar features were reported previously $[18,27,40]$. The bands at 975,1050 and $1123 \mathrm{~cm}^{-1}$ are caused by the formation of binuclear surface complex between sulfate (originated from the reagent used in the synthesis) and ferrihydrite [18]. These features were not observed for the ferrihydrites exhibiting the $\mathrm{Si} / \mathrm{Fe}$ molar ratio higher than 0.1 . A doublet at $2360-2340 \mathrm{~cm}^{-1}$, as well as sharp peak at $668 \mathrm{~cm}^{-1}$ are related to stretching and antisymmetric stretching of the $\mathrm{CO}_{2}$ molecule, respectively [16], and are not an inherent feature of the samples.

\section{Magnetic susceptibility measurements}

Magnetic susceptibility $(\chi)$ values at $77 \mathrm{~K}$ decrease from $8.05 \times 10^{-6} \mathrm{~m}^{3} \mathrm{~kg}^{-1}$ for FHYD-000 to as low as $8.10 \times$ $10^{-7} \mathrm{~m}^{3} \mathrm{~kg}^{-1}$ for FHYD-150 (Fig. 1). This is an effect of increasing content of diamagnetic silica in the samples. Similar lowering of magnetic susceptibility was reported previously [20]. The RT $\chi$ measurements revealed values several times lower-from ca. $1.5 \times 10^{-6} \mathrm{~m}^{3} \mathrm{~kg}^{-1}$ for FHYD-000 to ca. $3.7 \times 10^{-7} \mathrm{~m}^{3} \mathrm{~kg}^{-1}$ for FHYD-150. Previous evaluations of 2-line ferrihydrite magnetic susceptibility provided results in the range of $1-2.7 \times$ $10^{-6} \mathrm{~m}^{3} \mathrm{~kg}^{-1}[5,20,34,57]$, and our data for PFh fit within these limits. However, because of a relatively large measurement error of magnetic susceptibility at RT, only the results of low temperature measurements $(77 \mathrm{~K})$ are discussed below.

\section{Thermal studies}

DTA curve of Si-free ferrihydrite shows typical dehydration endotherm with a maximum at $136{ }^{\circ} \mathrm{C}$ and sharp exotherm at ca. $460{ }^{\circ} \mathrm{C}$, related to hematite formation (Fig. 2). Although the latter peak has been usually observed at temperatures $<400{ }^{\circ} \mathrm{C}[1,2,58]$, a highertemperature exotherm was also obtained in several studies [37, 59-61]. A small mass loss (ca. 2.2 mass\%) recorded in the range of $600-800{ }^{\circ} \mathrm{C}$, originates from decomposition of relic sulfate. This additional feature is not visible on thermal patterns of higher-Si materials, but very weak QMS signal of $\mathrm{SO}_{2}$ still exists (not shown). As evidenced from infrared spectra, sulfate ions are strongly adsorbed onto ferrihydrite surface, hence retarding hematite crystallization. This is reflected by the shift of transformation exotherm. It has been also shown recently that ferrihydrite obtained from sulfate salts is slightly more thermally stable than obtained from nitrate [32]. A total mass loss of FHYD-000 is 21.28 mass\% and remains similar for all the samples studied. The losses are comparable with earlier measurements of both synthetic [5, 17, 35, 37, 39] and natural ferrihydrites [16, 25, 49], but are explicitly higher than theoretical water content ( $\sim 17$ mass \%), due to a high amounts of physisorbed water. A bend on DTA curves of low-Si samples at ca. $680{ }^{\circ} \mathrm{C}$ is an effect of applying preheated hematite-rich sample as inert material, because this is the Néel point of the mineral $[2,58]$. 
Fig. 1 Magnetic susceptibility values of unheated ferrihydrites and resulting hematites measured at $77 \mathrm{~K}$. The ratio of ferrihydrite to hematite susceptibility is also shown
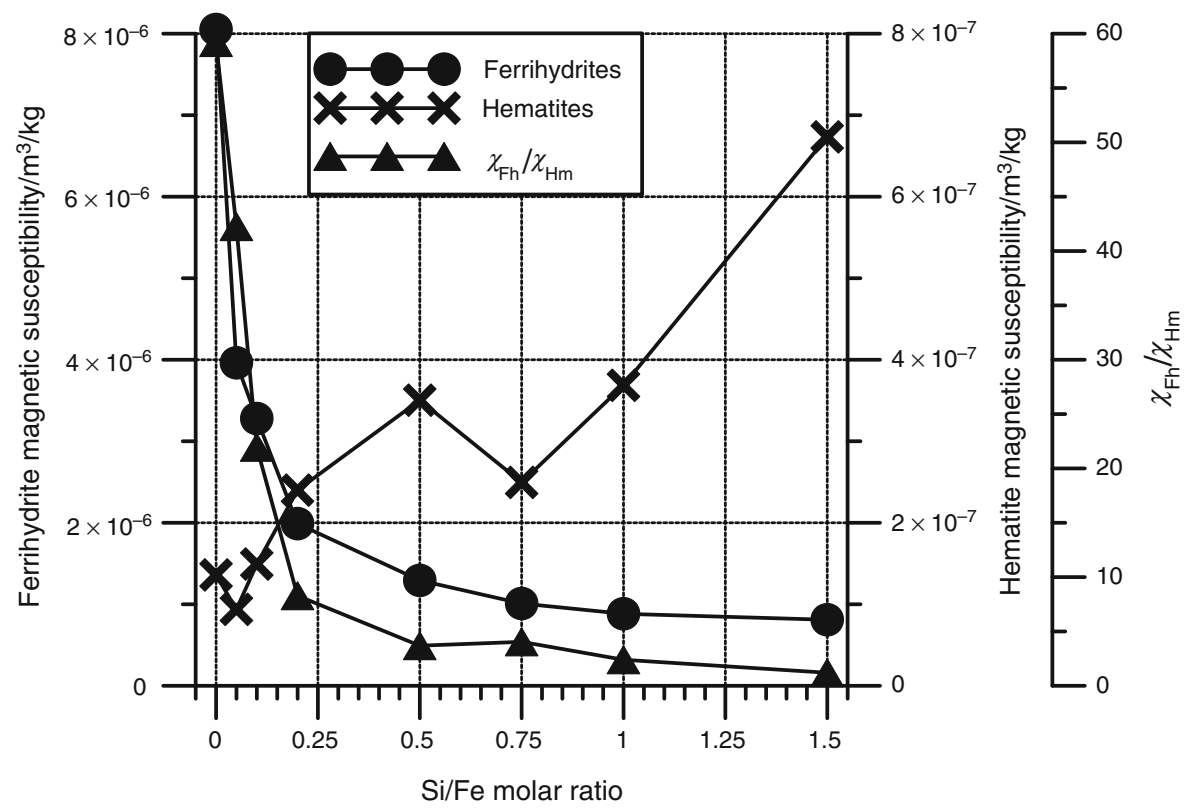

FHYD-000
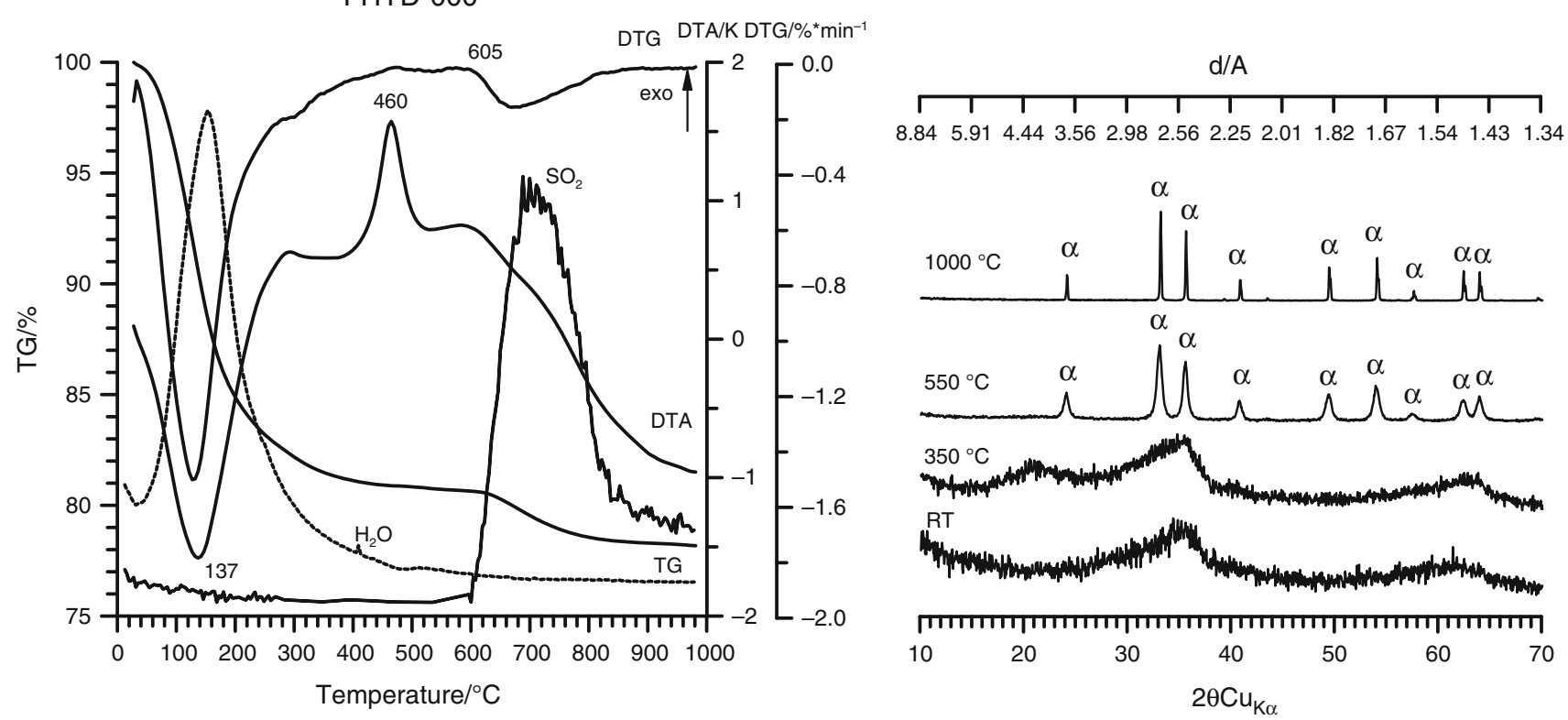

Fig. 2 DTA-TG-DTG plots and XRD patterns of the sample FHYD000 unheated and heated to different temperatures. QMS signals (not to scale, dashed lines) of $\mathrm{H}_{2} \mathrm{O}$ and $\mathrm{SO}_{2}$ are shown as well. The

The presence of $\mathrm{Si}$ in ferrihydrite hampers its conversion to hematite: A gradual weakening and broadening of the transformation exotherm is observed, as well as shifting of the peak position toward higher temperatures, up to ca. $900{ }^{\circ} \mathrm{C}$ for FHYD-150 (Figs. 3-9). For LSFh, a nearly linear relationship between $\mathrm{Si}$ content and the peak position exists (Figs. 3-5), which is in line with previous works $[24,40]$. However, no such relation has been found in numbers denote temperatures of processes/reactions. The background raising visible in the XRD pattern at $350{ }^{\circ} \mathrm{C}$ derives from a glass plate used in sample preparation

HSFh: For both FHYD-075 and FHYD-100 samples, the exotherm is located at $925{ }^{\circ} \mathrm{C}$ (Figs. 7, 8), and for FHYD150 , the peak is split into two broad maxima at 895 and $925{ }^{\circ} \mathrm{C}$ (Fig. 9). Additionally, some shifting of the lowtemperature dehydration endotherm has been observedHSFh appears to loose water at slightly higher temperatures than LSFh. The strong bend visible between approximately 600 and $900{ }^{\circ} \mathrm{C}$ in thermal patterns of high-Si ferrihydrites 

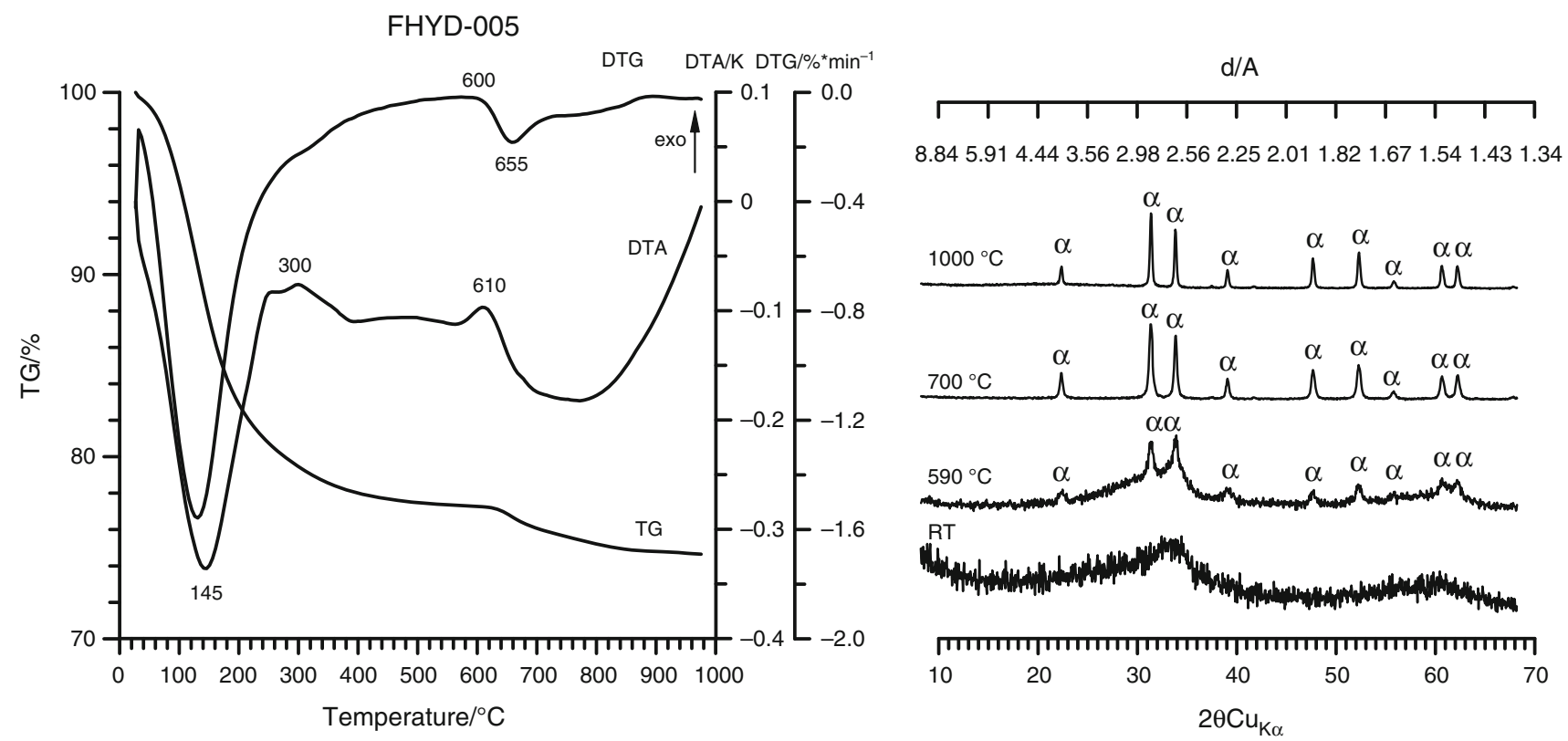

Fig. 3 DTA-TG-DTG plots and XRD patterns of the sample FHYD-005 unheated and heated to different temperatures. For explanations see Fig. 2

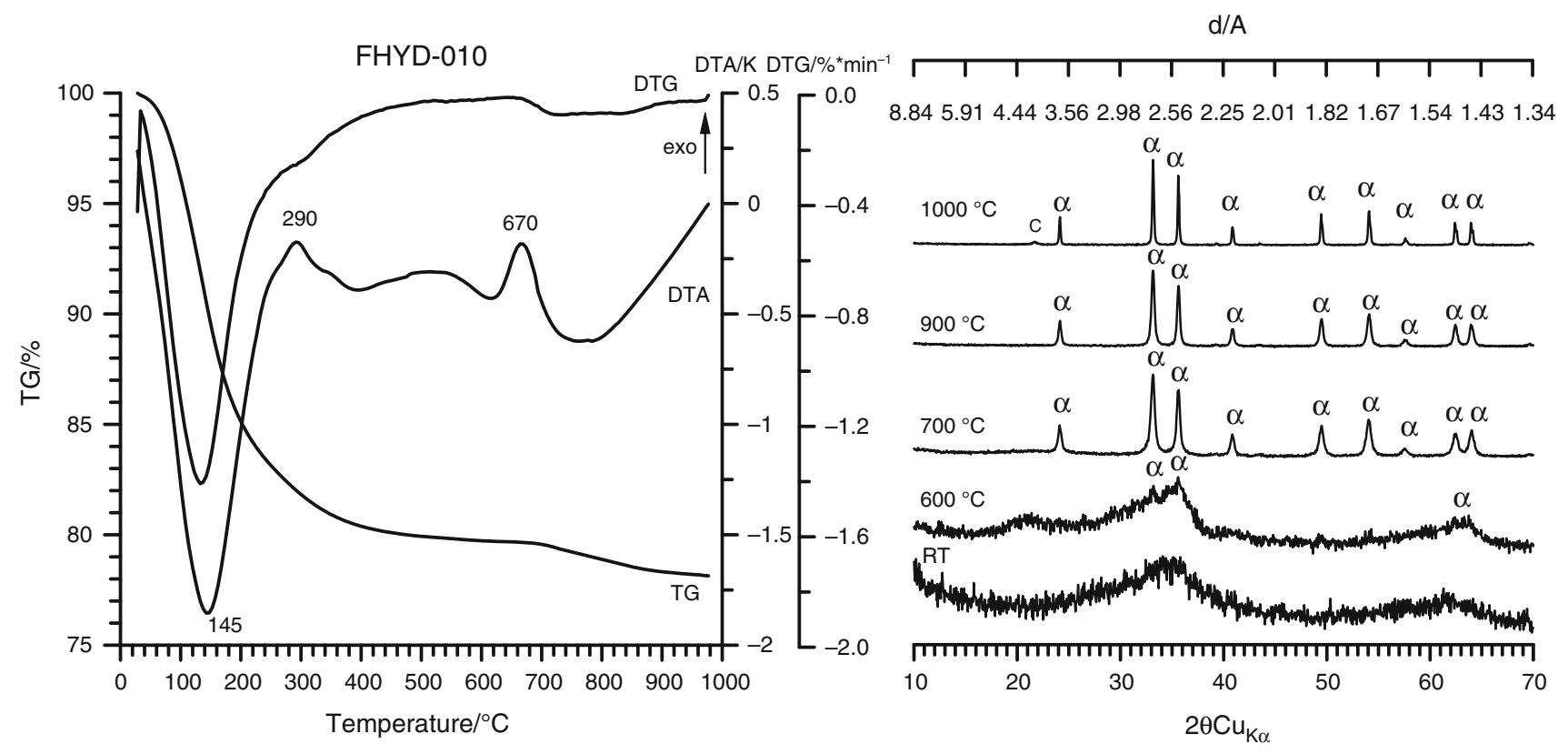

Fig. 4 DTA-TG-DTG plots and XRD patterns of the sample FHYD-010 unheated and heated to different temperatures. C-cristobalite

is not a real endotherm (Figs. 6-9), but is related to temperature-dependent differences in heat capacities and heat conductivities between the sample and the inert material.

\section{Hematites obtained by ferrihydrite annealing}

Bulk properties-XRD, FTIR and magnetic susceptibility

X-ray diffraction patterns (Figs. 2-9) indicate that the sole product of thermal transformation of $\mathrm{PFh}$ and the main product of the transformation of all $\mathrm{Si}$-ferrihydrites is hematite. All the Si-containing samples reveal the broadening of hematite reflections, indicating the decrease in its crystallinity. The broadening was most advanced in the FHYD-005 sample, and for LSFh, it clearly decreased with increasing $\mathrm{Si} / \mathrm{Fe}$ ratio (is to be published elsewhere). For high-Si materials, the broadening is less evident. This is consistent with earlier results [40]. Increasing $\mathrm{Si} / \mathrm{Fe}$ molar ratio $(\geq 0.10)$ in the initial material took an effect also in the appearance of cristobalite (Figs. 4-9). 


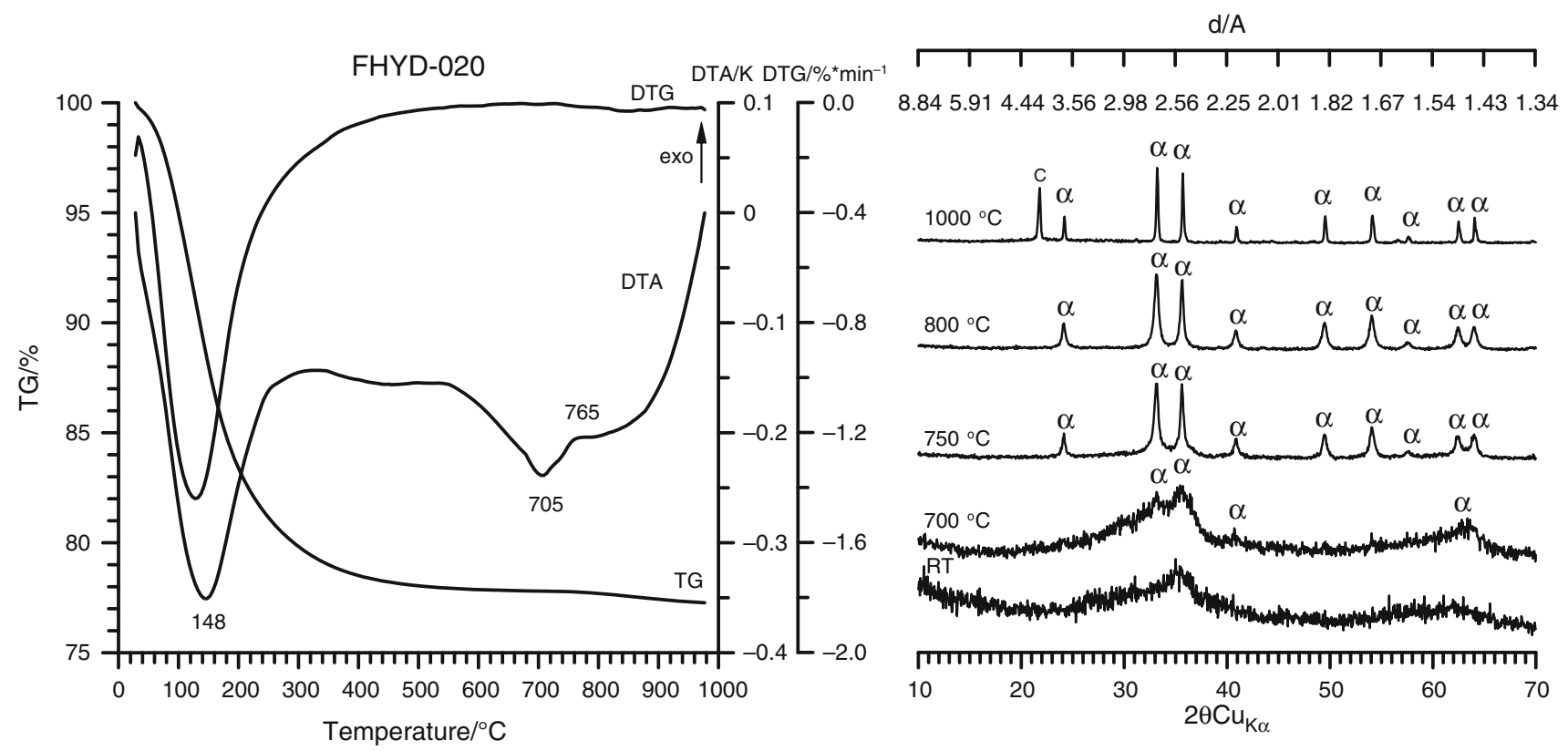

Fig. 5 DTA-TG-DTG plots and XRD patterns of the sample FHYD-020 unheated and heated to different temperatures. C-cristobalite

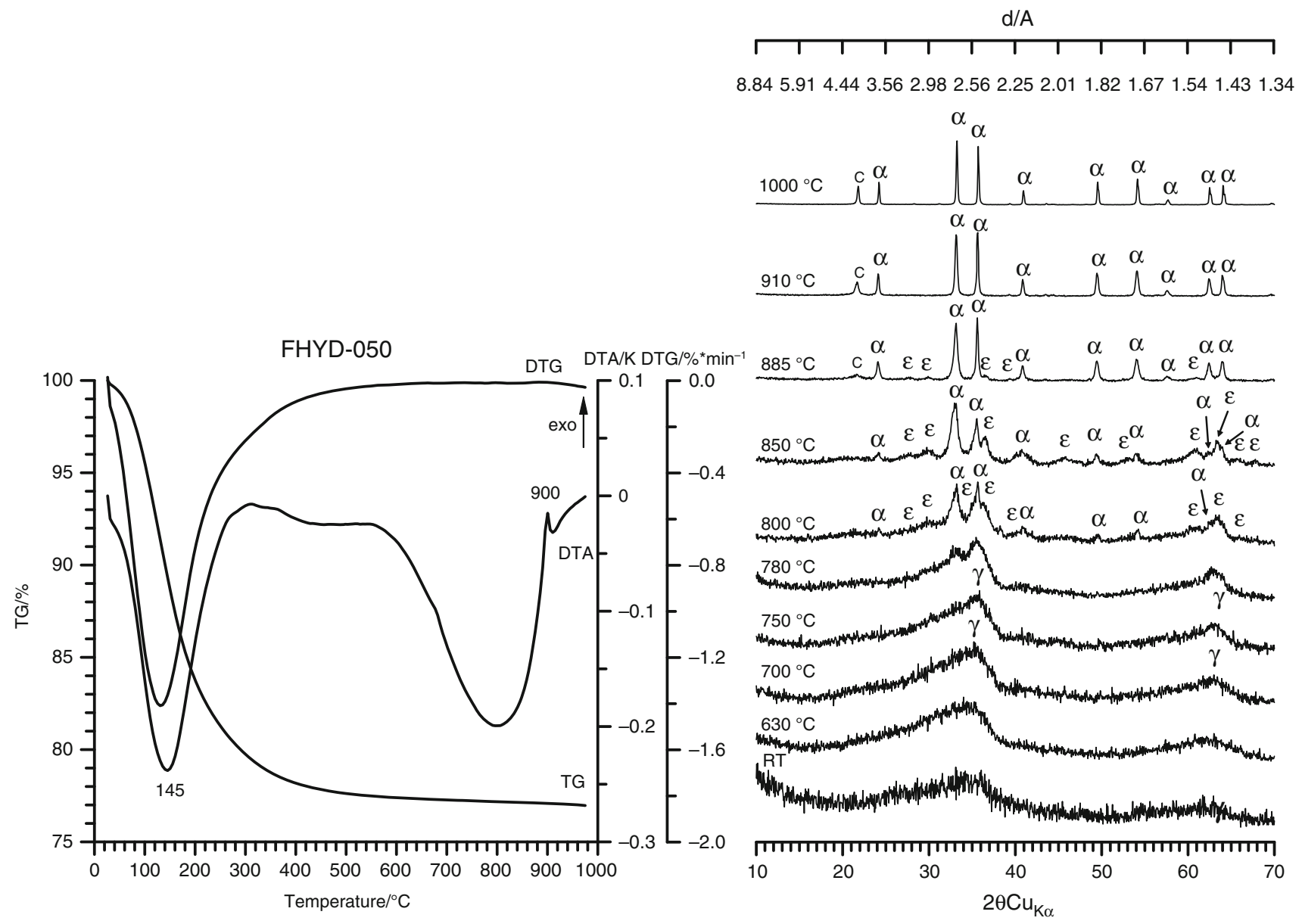

Fig. 6 DTA-TG-DTG plots and XRD patterns of the sample FHYD-050 unheated and heated to different temperatures. C-cristobalite 


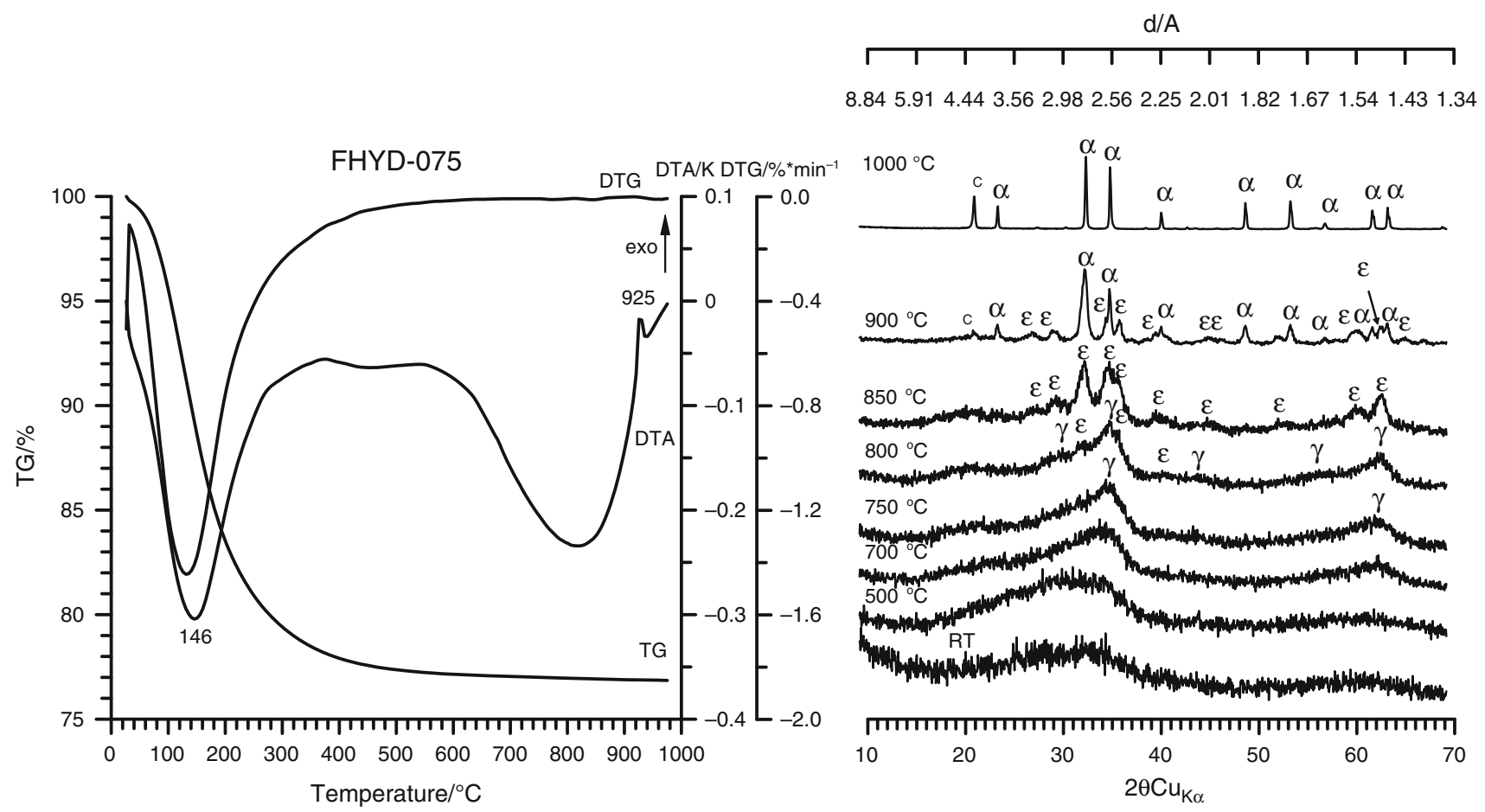

Fig. 7 DTA-TG-DTG plots and XRD patterns of the sample FHYD-075 unheated and heated to different temperatures. C-cristobalite
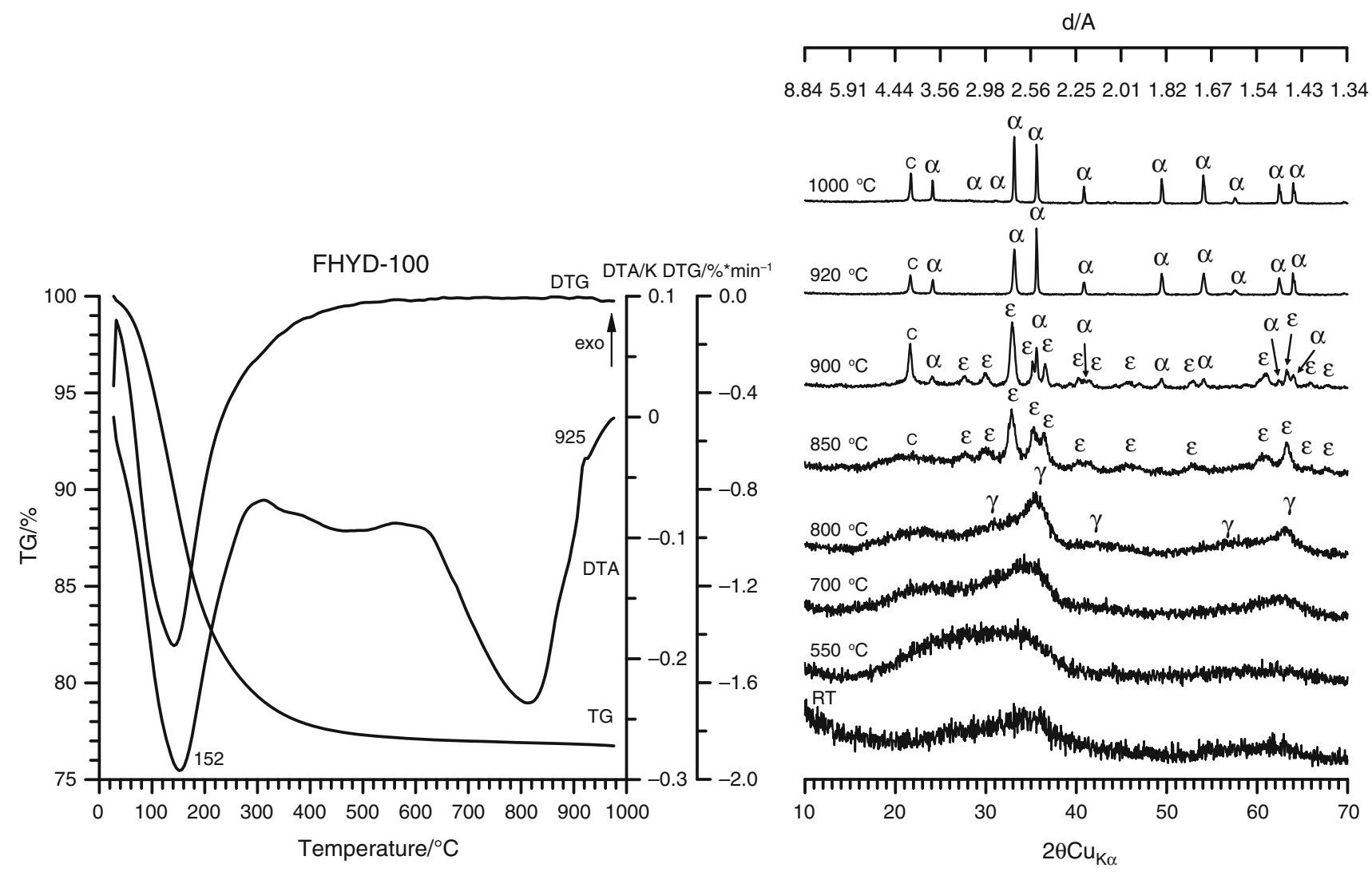

Fig. 8 DTA-TG-DTG plots and XRD patterns of the sample FHYD-100 unheated and heated to different temperatures. C-cristobalite 


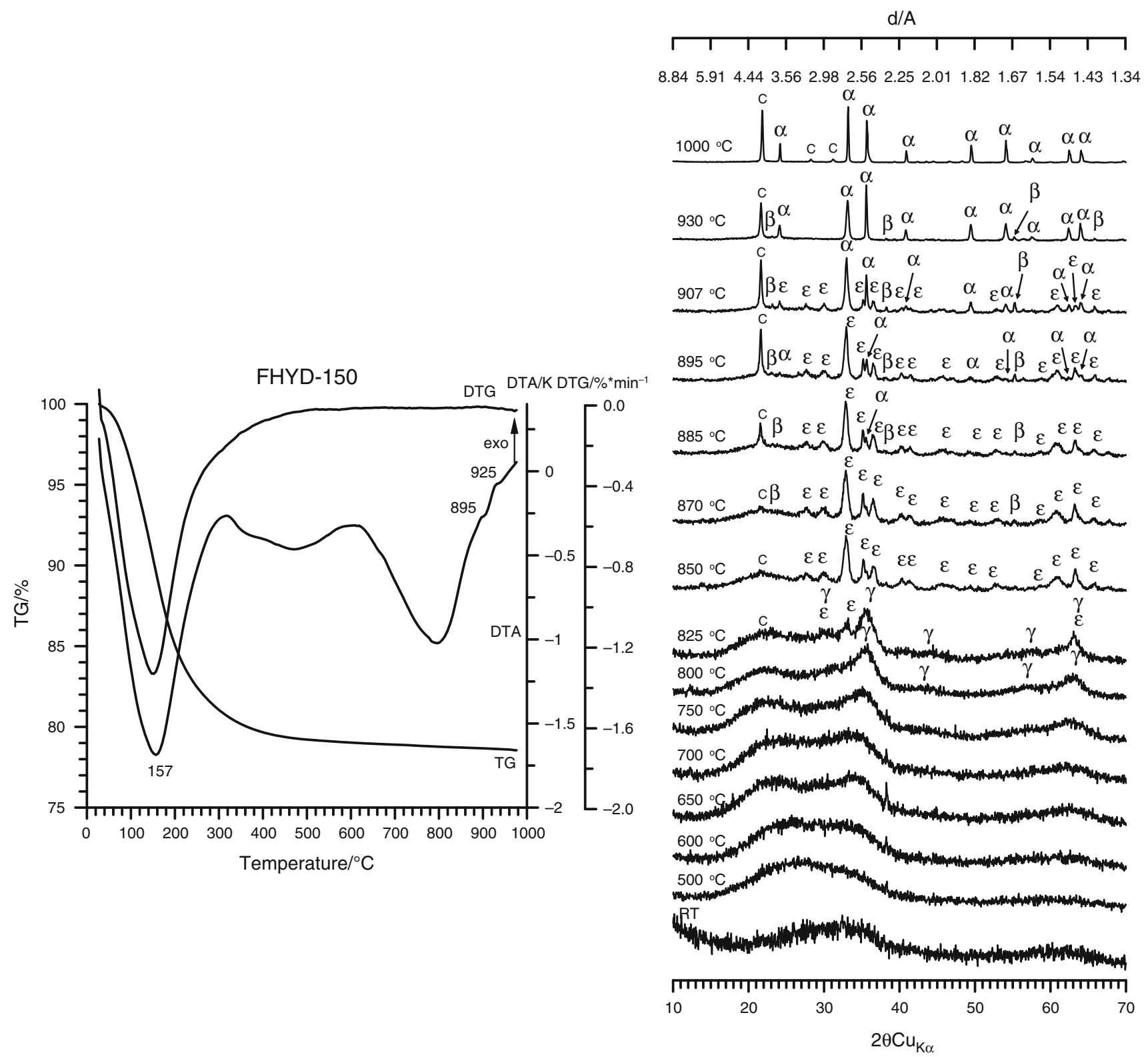

Fig. 9 DTA-TG-DTG plots and XRD patterns of the sample FHYD-150 unheated and heated to different temperatures. C-cristobalite

Infrared spectrum of annealed $\mathrm{PFh}$ reveals features at ca. 545,472 and $440 \mathrm{~cm}^{-1}$, typical for hematite [24, 39]. With increasing Si/Fe ratio, a slight shift of the $545 \mathrm{~cm}^{-1}$ band toward lower wave numbers is observed. The intensity of the peak at $472 \mathrm{~cm}^{-1}$ decreases at the same time, and in the spectra of the samples FHYD-005 to FHYD-020, this band occurs as a shoulder of the $445 \mathrm{~cm}^{-1}$ band. The features reflect differences in hematite crystallite morphology, because the position of these IR bands of $\alpha-\mathrm{Fe}_{2} \mathrm{O}_{3}$ are sensitive to the particle size and shape [2, 24, 40, 62]. It is also indicated by hematite SEM images (see below). For the hematites obtained from HSFh, a sharp peak ca. $790 \mathrm{~cm}^{-1}$ appears, due to siloxane ( $\mathrm{Si}-\mathrm{O}-\mathrm{Si})$ vibrations [24]. An intensive band at ca. $1080 \mathrm{~cm}^{-1}$, visible for all Si-containing samples, is an effect of $\mathrm{Si}-\mathrm{O}$ stretching [24]. The feature has been reported as typical cristobalite band [54] as well as $615,472 \mathrm{~cm}^{-1}$ bands and the shoulders at $\sim 1050$ and $\sim 1200 \mathrm{~cm}^{-1}$, which can be found for HSFh.

Magnetic susceptibilities of annealed samples are substantially lower $\left(1.37 \times 10^{-7} \mathrm{~m}^{3} \mathrm{~kg}^{-1}\right.$ for FHYD-000 to $6.73 \times 10^{-7} \mathrm{~m}^{3} \mathrm{~kg}^{-1}$ for FHYD-150) than those measured for unheated samples (Fig. 1, compare the scales), which is consistent with previous works [2, 5, 20,34]. However, the 
increasing $\mathrm{Si} / \mathrm{Fe}$ ratio appears to increase magnetic susceptibility of the annealed product (Fig. 1).

\section{Crystal sizes and shapes}

Hematite originated from heating of Si-free ferrihydrite forms quite large (up to $1 \mu \mathrm{m}$ in size) isometric and prismatic crystals (Fig. 10), which often exhibit hexagonal shape. Such a habit is typical for the oxide crystallizing in the absence of additives [2]. Almost identical images of hematite obtained by heating of (carbonated) 2-line ferrihydrite at $1000{ }^{\circ} \mathrm{C}$ were presented previously [55]. The oxide particles become twenty times smaller in the lowestsilicate material $(\mathrm{Si} / \mathrm{Fe}=0.05)$ and reveal spheroidal morphology (Fig. 10). However, hematites obtained by annealing FHYD-010 and FHYD-020 samples are distinctly larger than those originating from FHYD-005 sample (Figs. 10,11), which is in line with XRD results. In higher-silicate products, the crystallites are embedded in cryptocrystalline silica and exhibit wider range of crystal habits-isometric grains, plates, rods and even needles were encountered (Fig. 10). Elongated crystallites (rods and needles) are more common in the highest-Si products, which are reflected by the increase in average aspect ratios. A distinct increase in the aspect ratio distribution, estimated by standard deviations, evidences increasing heterogeneity of hematite habits (Fig. 11) and suggests various transformation routes. These findings are contrasting with the previous data [24] that spheroidal hematite particles formed from $\mathrm{Si}$-ferrihydrite, irrespective of the $\mathrm{Si}$ / Fe molar ratio. That work, however, involved narrower range of $\mathrm{Si} / \mathrm{Fe}$ ratios (up to 0.75 ).

\section{Transformation pathways}

\section{Pure ferrihydrite}

$\mathrm{PFh}$ heated to $350{ }^{\circ} \mathrm{C}$ reveals the increase in relative intensity and the decrease in FWHM of broad XRD peaks (Fig. 2). Due to dehydration and dehydroxylation, the intensities of IR bands at 3385 and $1635 \mathrm{~cm}^{-1}$ decrease. Additionally, the band at ca. $592 \mathrm{~cm}^{-1}$ becomes less intense and is shifted to ca. $570 \mathrm{~cm}^{-1}$. At $550{ }^{\circ} \mathrm{C}$, highly disordered hematite is the sole transformation product (Fig. 2), which is evidenced by both XRD and FTIR. However, the bands at $\sim 3400$ and $1635 \mathrm{~cm}^{-1}$ as well as $\sim 1130$ and $980 \mathrm{~cm}^{-1}$, attributable to $\mathrm{OH}$ and $\mathrm{SO}_{4}$ vibrations, respectively, are still visible in the FTIR spectra. This is in agreement with thermal analysis, because at $550{ }^{\circ} \mathrm{C}$, the plateau of $\mathrm{H}_{2} \mathrm{O}$ release is not yet attained and sulfates begin to decompose only at ca. $600{ }^{\circ} \mathrm{C}$ (Fig. 2). Therefore, the proper (stoichiometric) hematite is developed at higher temperatures [24, 40, 63]. Magnetic susceptibilities are gradually lowered in the temperature range of $25-550{ }^{\circ} \mathrm{C}$, and then, i.e., after hematite crystallization, only slight further lowering is observed (Fig. 12).

\section{Low-Si ferrihydrites (Si/Fe 0.05-0.20)}

Similar LSFh transformations were found. After low-temperature dehydration, gradual increase in XRD peak intensities and gradual decrease in their widths are observed. Up to $500{ }^{\circ} \mathrm{C}$, no distinct phase conversion is evidenced from XRD patterns. In FTIR spectra of FHYD010 sample, a shift of the $935 \mathrm{~cm}^{-1}$ band to $980 \mathrm{~cm}^{-1}$ just before the transformation to hematite $\left(600{ }^{\circ} \mathrm{C}\right)$ and to $1030 \mathrm{~cm}^{-1}$ just after the conversion $\left(700^{\circ} \mathrm{C}\right)$ indicates the breakup of $\mathrm{Si}-\mathrm{O}-\mathrm{Fe}$ linkages and subsequent formation of silica phase. In comparison with PFh, the most important difference is the distinct increase in temperature of transformation to hematite (Figs. 3-5). The just-formed $\alpha$ $\mathrm{Fe}_{2} \mathrm{O}_{3}$ is initially poorly crystalline, but further heating results in the increase in crystallinity (Figs. 3-5). The formation of cristobalite takes place at high temperaturesin XRD patterns of FHYD-010 (Fig. 4) and FHYD-020 samples (Fig. 5) cristobalite is recognizable only at $1000{ }^{\circ} \mathrm{C}$. This is confirmed by FTIR analysis. Interestingly, cristobalite is not present in FHYD-005 sample (or is below detection limit). Even at $1000{ }^{\circ} \mathrm{C}$, only the background raising at 15-30 two-theta degrees is apparent (which is hardly visible in Fig. 3). Similar phenomenon observed previously during heating of relatively low-Si ferrihydrites was linked with the formation of extremely poorly crystalline $\mathrm{Si}-\mathrm{O}-\mathrm{Fe}$ phase [40].

Magnetic susceptibility value of the FHYD-010 sample slightly increases (from 3.28 to $3.88 \times 10^{-6} \mathrm{~m}^{3} \mathrm{~kg}^{-1}$, measurements at $77 \mathrm{~K}$ ) just before the conversion to hematite (Fig. 12). Then it drops significantly to approximately $1.5 \times 10^{-6} \mathrm{~m}^{3} \mathrm{~kg}^{-1}$, when hematite forms, and to as low as ca. $1.5 \times 10^{-7} \mathrm{~m}^{3} \mathrm{~kg}^{-1}$, after finishing of the heating. Therefore, according to previous studies [5, 20, 33, 64], anion-doping of ferrihydrite appears to enhance magnetic susceptibility of dehydrated oxyhydroxide prior to its conversion to hematite.

\section{High-Si ferrihydrites (Si/Fe 0.50-1.50)}

For the FHYD-050 sample, the transformation pathway is similar to $\mathrm{LSFh}$ up to at least $600{ }^{\circ} \mathrm{C}$ - the material still exhibits two-peak ferrihydrite-like XRD pattern (Fig. 6), and FTIR spectrum possesses similar features as FHYD010 spectrum prior to transformation. X-ray diffractograms reveal virtually no phase transformations between 600 and $750{ }^{\circ} \mathrm{C}$ (Fig. 6), but magnetic susceptibility increases by almost order of magnitude, from ca. $1 \times 10^{-6} \mathrm{~m}^{3} \mathrm{~kg}^{-1}$ at $600{ }^{\circ} \mathrm{C}$ up to $8.6 \times 10^{-6} \mathrm{~m}^{3} \mathrm{~kg}^{-1}$ at $750{ }^{\circ} \mathrm{C}$ (Fig. 12) and 
Fig. 10 Secondary electron micrographs of hematite resulting from ferrihydrite annealing. The histograms of particle size distributions are shown in the insets (on the basis of the longer dimension in micrometers, $n$ the number of measured particles; note different dimension scale for lower- and higher-Si samples)
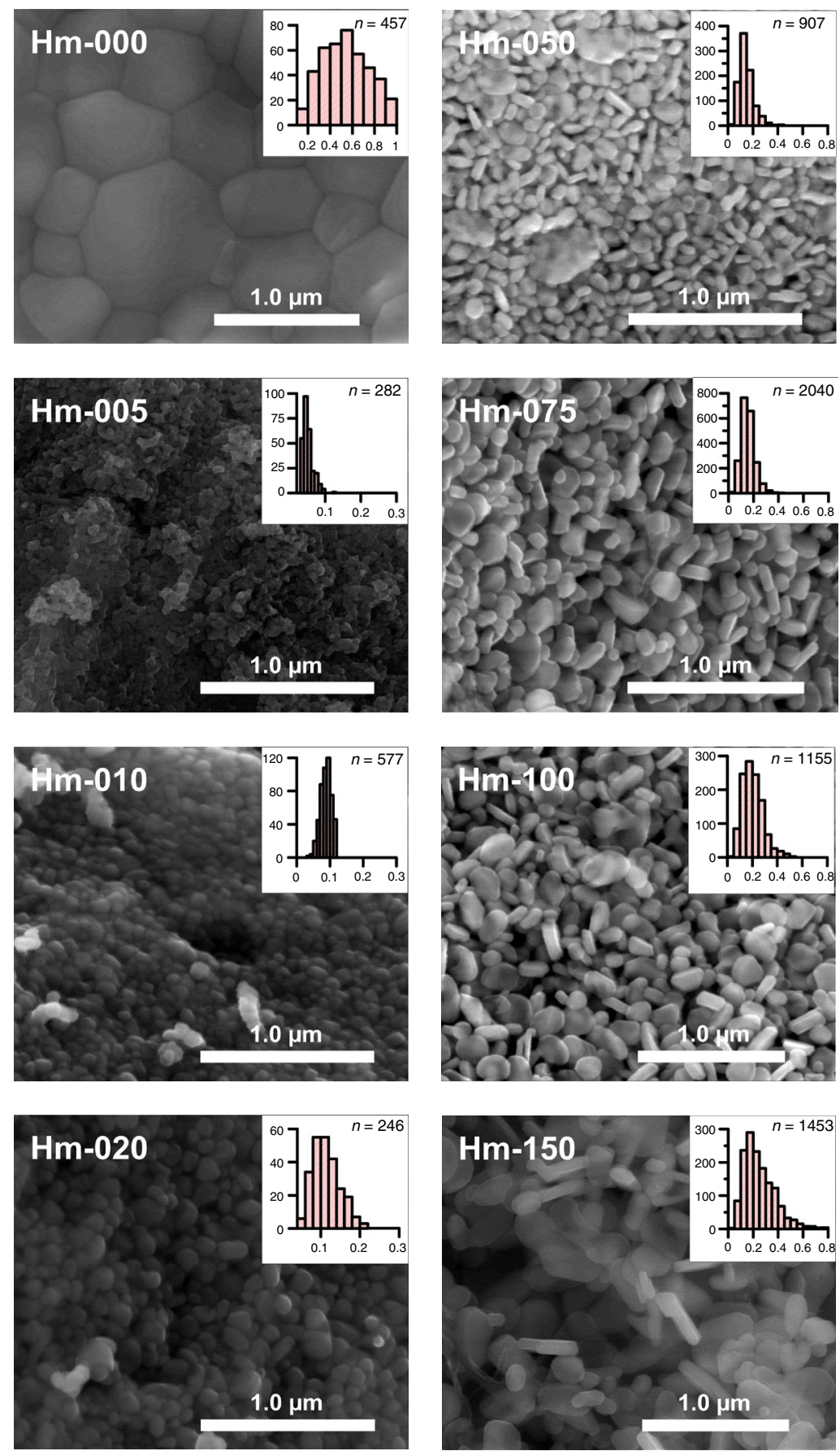

further to $1.36 \times 10^{-5} \mathrm{~m}^{3} \mathrm{~kg}^{-1}$ at $800{ }^{\circ} \mathrm{C}$. In the FTIR spectra, two additional shoulders at ca. $570 \mathrm{~cm}^{-1}$ and ca. $1200 \mathrm{~cm}^{-1}$ become visible at the same time, and the band at ca. $1000 \mathrm{~cm}^{-1}$ is shifted to ca. $1060 \mathrm{~cm}^{-1}$. The shift as well as the appearance of shoulder near $1200 \mathrm{~cm}^{-1}$ is a result of amorphous silica release, which is also reflected in XRD pattern, where a small background raising between $20^{\circ}$ and $30^{\circ} 2 \Theta$ is observed (Fig. 6). Therefore, some kind of phase transition is feasible at $700-750{ }^{\circ} \mathrm{C}$. The formation of nanocrystalline maghemite or 'ferrimagnetic ferrihydrite' [5] seems likely, because both these phases bring on distinct increase in magnetic susceptibility and were previously noticed during heating of (anion-doped) ferrihydrite. Transient nanomaghemite was reported in the course of annealing of various $\mathrm{SiO}_{2}-\mathrm{Fe}_{2} \mathrm{O}_{3}$ mixtures and nanocomposites [e.g., 65, 66], and for extremely fine-sized 


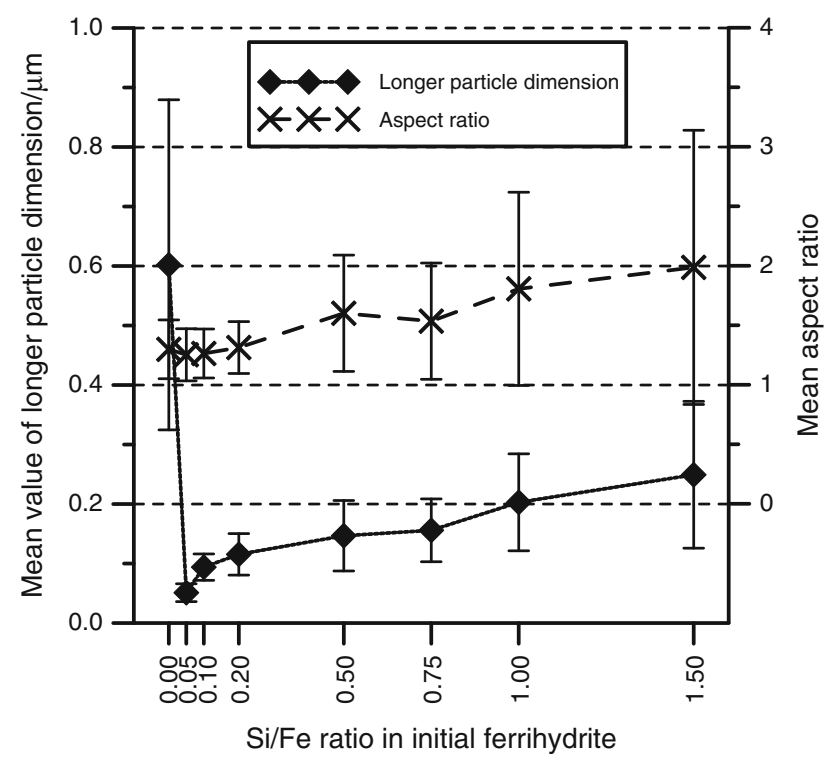

Fig. 11 Average longer dimensions (diamonds) and aspect ratios (crosses) of hematite particles versus $\mathrm{Si} / \mathrm{Fe}$ molar ratio of initial ferrihydrites. Dimension and aspect ratio variability is expressed as standard deviations (whiskers)

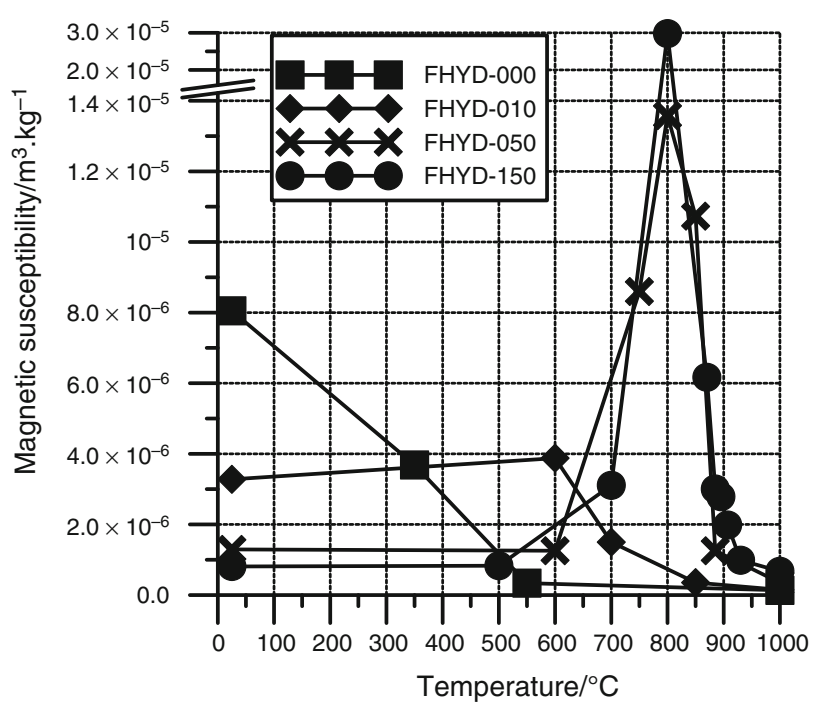

Fig. 12 Magnetic susceptibility values (measured at $77 \mathrm{~K}$ ) of ferrihydrites annealed to different temperatures

particles only two broad diffraction maxima were observed at ca. 2.50 and $1.475 \AA$, i.e., exactly the same positions as in the case of FHYD-050 sample. Gradual rising of the band at ca. $570 \mathrm{~cm}^{-1}$ in the FTIR spectra also supports the presence of nanomaghemite.

In the XRD pattern of the FHYD-050 sample heated at $800{ }^{\circ} \mathrm{C}$, nanomaghemite is replaced with a series of nanocrystalline hematite peaks (Fig. 6) and additional reflections, attributed to $\varepsilon-\mathrm{Fe}_{2} \mathrm{O}_{3}$ [67]. The transformation is also reflected in FTIR spectra-besides silica feature at ca. $800 \mathrm{~cm}^{-1}$, two new bands at 685 and $530 \mathrm{~cm}^{-1}$ appear at $800{ }^{\circ} \mathrm{C}$ and the additional shoulder ca. $600 \mathrm{~cm}^{-1}$ at $850{ }^{\circ} \mathrm{C}$. Similar FTIR features were reported for $\varepsilon-\mathrm{Fe}_{2} \mathrm{O}_{3}$ [68]. Therefore, between 800 and $885{ }^{\circ} \mathrm{C}$, two $\mathrm{Fe}_{2} \mathrm{O}_{3}$ polymorphs (alpha and epsilon) coexist in the sample. XRD pattern of the FHYD-050 sample annealed to $910{ }^{\circ} \mathrm{C}$ reveals the presence of cristobalite and hematite only (Fig. 6), hence the sharp exotherm on the DTA curve at $900{ }^{\circ} \mathrm{C}$ (Fig. 6) is related to the transformation of $\varepsilon-\mathrm{Fe}_{2} \mathrm{O}_{3}$ to $\alpha-\mathrm{Fe}_{2} \mathrm{O}_{3}$. Above the temperature, hematite is the sole iron oxide present in the annealing product and the narrowing of XRD peaks due to improving of crystallinity is observed.

The general course of thermal transformations during annealing of higher-Si samples is similar to that of FHYD050, but the reaction temperatures as well as some of the details are varying among the samples. The materials still exhibit two-peak ferrihydrite-like XRD pattern, but, in contrast to lower-Si samples, a broadening of the 110 peak toward lower two-theta angles is observed at $500-600{ }^{\circ} \mathrm{C}$ (Fig. 7-9). At the same time, an incremental shifting of $\mathrm{Si}-$ $\mathrm{O}$ band at ca. $1000 \mathrm{~cm}^{-1}$ toward higher wavenumbers up to ca. $1045 \mathrm{~cm}^{-1}$ appears in FTIR spectrum of FHYD-150 sample in this temperature range. A progressive release of silica from ferrihydrite explains these observations. Amorphous silica formation results in separation at $650-700{ }^{\circ} \mathrm{C}$ of formerly one broad band into two broad peaks at ca. 3.9 and 2.5-2.6 $\AA$ (Fig. 7-9). This is followed by the formation of nanocrystalline maghemite between 700 and $800{ }^{\circ} \mathrm{C}$. In the XRD patterns, only a few very broad peaks are recognizable (Figs. 7-9), which is consistent with other works [e.g., 65, 68]. The formation of nanomaghemite results in substantial increase in magnetic susceptibility (Fig. 12). Lower $\chi$ values compared to 4-20 $\times 10^{-4} \mathrm{~m}^{3} \mathrm{~kg}^{-1}$ of pure maghemite [2] results from both poor crystallinity and lower $\mathrm{Fe}$ content in the sample.

Subsequently, nanomaghemite is transformed to $\varepsilon$ $\mathrm{Fe}_{2} \mathrm{O}_{3}$ at $800-850{ }^{\circ} \mathrm{C}$, which is evidenced by both XRD (Figs. 7-9) and FTIR. $\varepsilon-\mathrm{Fe}_{2} \mathrm{O}_{3}$ is stable up to ca. $920{ }^{\circ} \mathrm{C}$. In the samples of 0.75 and $1.0 \mathrm{Si} / \mathrm{Fe}$ ratios, further increase in temperature $\left(>920{ }^{\circ} \mathrm{C}\right)$ results in $\varepsilon-\mathrm{Fe}_{2} \mathrm{O}_{3}$ conversion to hematite and crystallization of cristobalite (Figs. 7, 8). In turn, XRD patterns of annealed highest-Si sample ( $\mathrm{Si} /$ $\mathrm{Fe}=1.5)$ show also the presence of additional $\beta-\mathrm{Fe}_{2} \mathrm{O}_{3}$ phase between $907{ }^{\circ} \mathrm{C}$ and $930{ }^{\circ} \mathrm{C}$. At $907{ }^{\circ} \mathrm{C}$ hematite appears, and $\varepsilon-\mathrm{Fe}_{2} \mathrm{O}_{3}$ vanishes by $930{ }^{\circ} \mathrm{C}$ (Fig. 9), so at the latter temperature, two $\mathrm{Fe}_{2} \mathrm{O}_{3}$ polymorphs $(\alpha$ and $\beta$ ) are present. Therefore, two exotherms on DTA curve at 895 and $925{ }^{\circ} \mathrm{C}$ (Fig. 9) could be explained by crystallization of $\beta-\mathrm{Fe}_{2} \mathrm{O}_{3}$ and recrystallization of $\varepsilon-\mathrm{Fe}_{2} \mathrm{O}_{3}$ to hematite, respectively. At $1000{ }^{\circ} \mathrm{C}$, hematite is the sole iron oxide in all the products. 


\section{The role of $\mathrm{Si}$ in thermal transformation of ferrihydrite}

In the case of the annealed Si-ferrihydrites, the major factor that appears to affect both the transformation routes and the properties of the products is Si content in pristine oxyhydroxide. Silicate stabilizes ferrihydrite structure and hampers its conversion to hematite. The shifting of the transformation reaction to higher temperatures is caused by the inhibiting effect of silicate on rearrangement processes within ferrihydrite particles which are necessary for structural ordering and conversion into the oxide [2]. For this reason, the hematite crystallinity is distinctly decreased as well. In our study, the lowest-Si ferrihydrite was converted into the smallest-sized hematite, and the increasing $\mathrm{Si}$ content appeared to increase the hematite particle dimensions (Figs. 10, 11). It was previously suggested [40] that small amounts of Si could enter the hematite structure during Siferrihydrite annealing, but were ejected when higher annealing temperature was achieved. It might be a reason for poor crystal development when hematite originated from conversion of low-Si ferrihydrite. Because $\mathrm{Si}$ is coordinated tetrahedrally, it is hardly possible to enter the structure of stoichiometric hematite, where all (iron) cations occupy octahedral positions. On the other hand, initially formed non-stoichiometric hematite is highly disordered and, as evidenced by thermal analyses and FTIR, still contains some hydroxyls and trace sulfates. Therefore, incorporation of silicate in such disordered lattice appears to be more plausible. When heating is prolonged to higher temperature, hydroxyls and silicates would be ejected from the structure and stoichiometric, but fine-crystalline hematite is formed.

Heating of HSFh runs differently, because silicate bound to the oxyhydroxide surface is gradually polymerized and crystallizes thus forming a kind of matrix, in which the particles of dehydr(oxyl)ated ferrihydrite and nanomaghemite are embedded. In the absence of such matrix, maghemite always undergoes the conversion to hematite $[2,51]$. However, the matrix hampers the coalescence, avoids the agglomeration of the particles and keeps their sizes quite constant. Because, as it was hypothesized earlier, the phase conversion of $\gamma-\mathrm{Fe}_{2} \mathrm{O}_{3}$ to $\alpha-\mathrm{Fe}_{2} \mathrm{O}_{3}$ takes place once the maghemite nanoparticles reach a critical size of 10-25 nm [51], the cristobalite-like mass would inhibit the hematite crystallization. Therefore, an analogue of $\mathrm{SiO}_{2}$-maghemite nanocomposite is formed, which has been reported to enhance maghemite thermal stability and favor its transformation to hematite via indirect mechanisms $[51,69,70]$. The specific conditions that are developed allow to the formation of rare polymorphic forms (i.e., $\varepsilon-\mathrm{Fe}_{2} \mathrm{O}_{3}$ and $\beta-\mathrm{Fe}_{2} \mathrm{O}_{3}$ ), impossible to stabilize otherwise [71]. These polymorphs exhibit different habits transmission electron microscopic observations (to be presented elsewhere) reveal rods of epsilon phase and cubes of beta phase. Further annealing of the samples (above approximately $920-930{ }^{\circ} \mathrm{C}$ ) causes the conversion of these intermediates into hematite, and the latter can inherit the precursor habits. For these reasons, the hematites obtained during annealing of HSFh exhibit various crystal shapes, reflected in, for example, the high variability of aspect ratios (Figs. 10, 11). However, particular mechanisms which control $\beta-\mathrm{Fe}_{2} \mathrm{O}_{3}$ formation besides $\varepsilon$ $\mathrm{Fe}_{2} \mathrm{O}_{3}$ remain unclear. It was hypothesized recently [72] that free energies of nanoparticles play dominant role here, but later works showed that the character of the starting compound and the synthesis conditions appeared to be more important [53].

\section{Conclusions}

Our study demonstrates that silicate content retards ferrihydrite thermal transformation to hematite and affects crystallinity of the latter. The properties of resulting hematite, as well as transformation pathways, are highly dependent on $\mathrm{Si} / \mathrm{Fe}$ molar ratio. In general, higher $\mathrm{Si} / \mathrm{Fe}$ molar ratios result in more complex transformations. The most important observations and conclusions are as follows:

1. When Si admixture is lower than $0.2 \mathrm{~mol} \mathrm{~mol}^{-1} \mathrm{Fe}$, then ferrihydrite nanoparticles are stabilized by adsorbed silicate and the conversion to $\alpha-\mathrm{Fe}_{2} \mathrm{O}_{3}$ is hindered. Magnetic susceptibility is slightly increased prior to the transformation, but no distinct intermediate is formed. The crystal size of all resulting hematites is distinctly reduced compared to the product of pure ferrihydrite annealing, but increases with increasing $\mathrm{Si} /$ Fe molar ratio.

2. When $\mathrm{Si} / \mathrm{Fe}$ ratio in pristine ferrihydrite is higher, silicate progressively polymerizes with increasing temperature and forms a sort of matrix in which iron compounds are embedded. The aggregation of iron oxide nanoparticles is impeded, and the conditions favoring crystallization of intermediate phases arise. A distinct increase in magnetic susceptibility is observed at the same time.

3. The intermediates include nanocrystalline maghemite, followed by rare iron oxide polymorphs: $\varepsilon-\mathrm{Fe}_{2} \mathrm{O}_{3}$ and - in the case of the highest-Si material-also $\beta$ $\mathrm{Fe}_{2} \mathrm{O}_{3}$.

4. Hematite, which is the sole $\mathrm{Fe}_{2} \mathrm{O}_{3}$ polymorph at $1000{ }^{\circ} \mathrm{C}$, can inherit the precursors' habits, hence its shape and size range significantly.

5. To the best of the authors' knowledge, $\varepsilon-\mathrm{Fe}_{2} \mathrm{O}_{3}$ and $\beta$ $\mathrm{Fe}_{2} \mathrm{O}_{3}$ have not been reported yet as a result of 
ferrihydrite heating (besides the short mention in [40]). Annealing of Si-ferrihydrites might therefore offer an alternative method of obtaining these rare polymorphs.

6. This work evidences that the formation of both epsilon and beta $\mathrm{Fe}_{2} \mathrm{O}_{3}$ is possible when siliceous ferrihydrites are heated to high temperature. Because Si-rich ferric (oxyhydro)oxide materials occur in some geological environments (e.g., in hydrothermal systems of midocean ridges), the formation of these rare $\mathrm{Fe}_{2} \mathrm{O}_{3}$ polymorphs seems plausible if specific conditions are met.

Acknowledgements This work was supported by AGH-UST statutory grant No. 11.11.140.319. Bartosz Budzyń is acknowledged for careful reading the manuscript. We also thank two anonymous reviewers whose constructive comments allowed improving the clarity of the manuscript.

Open Access This article is distributed under the terms of the Creative Commons Attribution 4.0 International License (http://creative commons.org/licenses/by/4.0/), which permits unrestricted use, distribution, and reproduction in any medium, provided you give appropriate credit to the original author(s) and the source, provide a link to the Creative Commons license, and indicate if changes were made.

\section{References}

1. Jambor JL, Dutrizac JE. Occurrence and constitution of natural and synthetic ferrihydrite, a widespread iron oxyhydroxide. Chem Rev. 1998;98:2549-85.

2. Cornell RM, Schwertmann U. The iron oxides: structure, properties, reactions, occurrences and uses. 2nd ed. Weinheim: Wiley; 2003.

3. Guo H, Barnard AS. Naturally occurring iron oxide nanoparticles: morphology, surface chemistry and environmental stability. J Mater Chem A. 2013;1:27-42.

4. Michel FM, Ehm L, Anato SM, Lee PL, Chupas PJ, Liu G, Strongin DR, Schoonen MAA, Phillips BL, Parise JB. The structure of ferrihydrite, a nanocrystalline material. Science. 2007;316:1726-8.

5. Michel FM, Barrón V, Torrent J, Morales MP, Serna CJ, Boily J-F, Liu Q, Ambrosini A, Cismasu AC, Brown GE Jr. Ordered ferrimagnetic form of ferrihydrite reveals links among structure, composition, and magnetism. PNAS. 2010;107:2787-92.

6. Rancourt DG, Meunier J-F. Constraints on structural models of ferrihydrite as a nanocrystalline material. Am Mineral. 2008;93: 1412-7.

7. Maillot F, Morin G, Wang Y, Bonnin D, Ildefonse P, Chaneac C, Calas G. New Insight into the structure of nanocrystalline ferrihydrite: EXAFS evidence for tetrahedrally coordinated iron(III). Geochim Cosmochim Acta. 2011;75:2708-20.

8. Xu W, Hausner DB, Harrington R, Lee PI, Strongin DR, Parise JB. Structural water in ferrihydrite and constraints this provides on possible structure models. Am Mineral. 2011;96:513-20.

9. Manceau A. Critical evaluation of the revised akdalite model for ferrihydrite. Am Mineral. 2011;96:521-33.

10. Paktunc D, Manceau A, Dutrizac J. Incorporation of Ge in ferrihydrite: implications for the structure of ferrihydrite. Am Mineral. 2013;98:848-58.
11. Hiemstra T. Surface and mineral structure of ferrihydrite. Geochim Cosmochim Acta. 2013;105:316-25.

12. Masina CJ, Neethling JH, Olivier EJ, Manzini S, Lodya L, Srot V, van Aken PA. Structural and magnetic properties of ferrihydrite nanoparticles. RSC Adv. 2015;5:39643-50.

13. Drits VA, Sakharov BA, Salyn AL, Manceau A. Structural model for ferrihydrite. Clay Miner. 1993;28:185-207.

14. Cismasu AC, Levard C, Michel FM, Brown GE Jr. Properties of impurity-bearing ferrihydrite II. Insights into the surface structure and composition of pure, Al- and Si-bearing ferrihydrite from $\mathrm{Zn}$ (II) sorption experiments and Zn K-edge X-ray absorption spectroscopy. Geochim Cosmochim Acta. 2013;119:46-60.

15. Toner BM, Berquó TS, Michel FM, Sorensen JV, Templeton AS, Edwards KJ. Mineralogy of iron microbial mats from Loihi Seamount. Front Microbiol. 2012;3:1-18.

16. Sun Z, Zhou H, Glasby GP, Sun Z, Yang Q, Yin Z, Li J. Mineralogical characterization and formation of $\mathrm{Fe}-\mathrm{Si}$ oxyhydroxide deposits from modern seafloor hydrothermal vents. Am Mineral. 2013;98:85-97.

17. Cismasu AC, Michel FM, Tcaciuc AP, Brown GE Jr. Properties of impurity-bearing ferrihydrite III. Effects of $\mathrm{Si}$ on the structure of 2-line ferrihydrite. Geochim Cosmochim Acta. 2014;133: $168-85$.

18. Vempati RK, Loeppert RH. Influence of structural and adsorbed $\mathrm{Si}$ on the transformation of synthetic ferrihydrite. Clays Clay Miner. 1989;37:273-9.

19. Swedlund PJ, Webster JG. Adsorption and polymerisation of silicic acid on ferrihydrite, and its effect on arsenic adsorption. Water Res. 1999;16:3413-22.

20. Cabello E, Morales MP, Serna CJ, Barrón V, Torrent J. Magnetic enhancement during the crystallization of ferrihydrite at 25 and $50{ }^{\circ} \mathrm{C}$. Clays Clay Miner. 2009;57:46-53.

21. Bolanz RM, Bläss U, Ackermann S, Ciobota V, Rösch P, Tarcea N, Popp J, Majzlan J. The effect of antimonate, arsenate and phosphate on the transformation of ferrihydrite to goethite, hematite, feroxyhite, and tripuhyite. Clays Clay Miner. 2013;61: $11-25$.

22. Pieczara G, Rzepa G, Zych $€$. An effect of Si content on surface properties of synthetic ferrihydrite (in Polish with English summary). In: Ratajczak T, Rzepa G, Bajda T, editors. Sorbenty mineralne. Kraków: Wyd. AGH; 2013. p. 347-60.

23. Vempati RK, Loeppert RH, Cocke DL. Mineralogy and reactivity of amorphous Si-ferrihydrites. Solid State Ionics. 1990;38:53-61.

24. Vempati RK, Loeppert RH, Sittertz-Bhatkar H, Burghardt RC. Infrared vibrations of hematite formed from aqueous- and drythermal incubation of Si-containing ferrihydrite. Clays Clay Miner. 1990;38:294-8.

25. Parfitt RL, Van der Gaast SJ, Childs W. A structural model for natural siliceous ferrihydrite. Clays Clay Miner. 1992;40:675-81.

26. Schwertmann U, Friedl J, Kyek A. Formation and properties of continuous crystallinity series of synthetic ferrihydrites (2- to 6-line) and their relation to $\mathrm{FeOOH}$ forms. Clays Clay Miner. 2004;52:221-6.

27. Seehra MS, Roy P, Raman A, Manivannan A. Structural investigations of synthetic ferrihydrite nanoparticles doped with Si. Solid State Commun. 2004;130:597-601.

28. Berquó TS, Banerjee SK, Ford RG, Penn RL, Pichler T. High crystallinity Si-ferrihydrite: an insight into its Néel temperature and size dependence of magnetic properties. J Geophys Res. 2007;112:B02102.

29. Dyer L, Fawell PD, Newman OMG, Richmond WR. Synthesis and characterization of ferrihydrite/silica co-precipitates. J Coll Interface Sci. 2010;348:65-70.

30. Dyer LG, Chapman KW, English P, Saunders M, Richmond WR. Insight into the crystal and aggregate structure of $\mathrm{Fe}^{+3}$ oxide/ silica co-precipitates. Am Mineral. 2012;97:63-9. 
31. Pokrovski GS, Schott J, Farges F, Hazeman J-L. Iron (III)-silica interactions in aqueous solution: insight from X-ray absorption fine structure spectroscopy. Geochim Cosmochim Acta. 2003; 67:3559-73.

32. Pieczara G, Mendsaikhan N, Manecki M, Rzepa G. The effect of synthesis method on the physicochemical properties of ferrihydrite and Si-doped ferrihydrite (in Polish with English summary). Przem Chem. 2015;94:1828-31.

33. Barrón V, Torrent J, de Grave E. Hydromaghemite, an intermediate in the hydrothermal transformation of 2-line ferrihydrite into hematite. Am Mineral. 2003;88:1679-88.

34. Barrón V, Torrent J. Evidence for a simple pathway to maghemite in Earth and Mars soils. Geochim Cosmochim Acta. 2002;66:2801-6.

35. Eggleton RA, Fitzpatrick RW. New data and a revised structural model for ferrihydrite. Clays Clay Miner. 1988;36:111-24.

36. Rhoton FE, Bigham JM, Lindbo DL. Properties of iron oxides in streams draining the Loess Uplands of Mississippi. Appl Geochem. 2002;17:409-19.

37. Liu H, Wang Y, Ma Y, Wei Y, Pan G. The microstructure of ferrihydrite and its catalytic activity. Chemosphere. 2010;79:802-6.

38. Zhao J, Huggins FE, Feng Z, Huffman GP. Ferrihydrite: surface structure and its effects on phase transformation. Clays Clay Miner. 1994;42:737-46.

39. Glasauer SM, Hug P, Weidler PG, Gehring AU. Inhibition of sintering by $\mathrm{Si}$ during the conversion of Si-rich ferrihydrite to hematite. Clays Clay Miner. 2000;48:51-6.

40. Campbell AS, Schwertmann U, Stanjek H, Friedl J, Kyek A, Campbell PA. Si incorporation into hematite by heating Si-ferrihydrite. Langmuir. 2002;18:7804-9.

41. Carlson L, Schwertmann U. Natural ferrihydrites in surface deposits from Finland and their association with silica. Geochim Cosmochim Acta. 1981;45:421-9.

42. Rzepa G, Bajda T, Gaweł A, Debiec K, Drewniak L. Mineral transformations and textural evolution during roasting of bog iron ores. J Therm Anal Calorim. 2016;123:615-30.

43. Hashimoto H, Fujii T, Kohara S, Nakanishi K, Yogi C, Peterlik H, Nakanishi M, Takada J. Structural transformations of heattreated bacterial iron oxide. Mater Chem Phys. 2015;155:67-75.

44. Herbillon AJ. Tran Vinh An J. Heterogeneity in silicon-iron mixed hydroxides. J Soil Sci. 1969;20:223-35.

45. Schwertmann U, Fechter H. The point of zero charge of natural and synthetic ferrihydrite and its relation to adsorbed silicate. Clay Miner. 1982;17:471-6.

46. Childs CW, Wells N, Downes CJ. Kokowai Springs, Mount Egmont, New Zealand; Chemistry and mineralogy of the ochre (ferrihydrite) deposit and analysis of the waters. J R Soc N Z. 1986;16:85-99.

47. Soma M, Seyama H, Yoshinaga N, Theng BKG, Childs CW. Bonding state of silicon in natural ferrihydrites by X-ray photoelectron spectroscopy. Clay Sci. 1996;9:385-91.

48. Filip J, Zboril R, Schneeweiss O, Zeman J, Cernik M, Kvapil P, Otyepka M. Environmental applications of chemically pure natural ferrihydrite. Environ Sci Technol. 2007;41:4367-74.

49. Boyd T, Scott SD. Two-XRD-line ferrihydrite and Fe-Si-Mn oxyhydroxide mineralization from Franklin Seamount, Western Woodlark Basin, Papua New Guinea. Can Miner. 1999;37:973-90.

50. Pichler T, Veizer J. Precipitation of Fe(III) oxyhydroxide deposits from shallow-water hydrothermal fluids in Tutum Bay, Ambitle Island, Papua New Guinea. Chem Geol. 1999;162:15-31.

51. Machala L, Tuček J, Zbořil R. Polymorphous transformations of nanometric iron(III) oxide: a review. Chem Mater. 2011;23:3255-72.

52. Tuček J, Zbořil R, Namai A, Ohkoshi S. $\varepsilon-\mathrm{Fe}_{2} \mathrm{O}_{3}$ : an advanced nanomaterial exhibiting giant coercive field, milimeter-wave ferromagnetic resonance, and magnetoelectric coupling. Chem Mater. 2010;22:6483-505.
53. Brázda $\mathrm{P}$, Kohout J, Bezdička $\mathrm{P}$, Kmječ T. $\alpha-\mathrm{Fe}_{2} \mathrm{O}_{3}$ versus $\beta$ $\mathrm{Fe}_{2} \mathrm{O}_{3}$ : controlling the phase of the transformation product of $\varepsilon-$ $\mathrm{Fe}_{2} \mathrm{O}_{3}$ in the $\mathrm{Fe}_{2} \mathrm{O}_{3} / \mathrm{SiO}_{2}$ system. Cryst Growth Des. 2014;14:1039-46.

54. Mazzetti L, Thistlethwaite PJ. Raman spectra and thermal transformations of ferrihydrite and schwertmannite. J Raman Spectrosc. 2002;33:104-11.

55. Vallina B, Rodriguez-Blanco JD, Brown AP, Benning LG, Blanco JA. Enhanced magnetic coercivity of $\alpha-\mathrm{Fe}_{2} \mathrm{O}_{3}$ obtained from carbonated 2-line ferrihydrite. J Nanopart Res. 2014;16:2322.

56. Ruan HD, Frost RL, Kloprogge JT, Duong L. Infrared spectroscopy of goethite dehydroxylation III. FT-IR microscopy of in situ study of the thermal transformation of goethite to hematite. Spectrochim Acta. 2002;58:967-81.

57. Pannalal SJ, Crowe SA, Cioppa MT, Symons DTA, Sturm A, Fowle DA. Room-temperature magnetic properties of ferrihydrite: a potential magnetic remanence carrier? Earth Planet Sci Lett. 2005;236:856-70.

58. Földvári M. Handbook of thermogravimetric system of minerals and its use in geological practice. Occasional Papers of the Geological Institute of Hungary, 213. Budapest: Geological Institute of Hungary; 2011.

59. Towe KM, Bradley WF. Mineralogical constitution of colloidal "hydrous ferric oxides". J Coll Interface Sci. 1967;24:384-92.

60. Campbell AS, Schwertmann U, Campbell PA. Formation of cubic phases on heating ferrihydrite. Clay Miner. 1997;32: 615-22.

61. Oliveira AC, Marchetti GS, do Carmo Rangel M. The effect of the starting material on the thermal decomposition of iron oxyhydroxides. J Therm Anal Calorim. 2003;73:233-40.

62. Rendon JL, Serna CJ. IR spectra of powder hematite: effect of particle size and shape. Clay Miner. 1981;16:357-81.

63. Peterson KM, Heaney PJ, Post JE, Eng PJ. A refined monoclinic structure for a variety o "hydrohematite". Am Mineral. 2015;100:570-9.

64. Liu Q, Barrón V, Torrent J, Eeckhout SG, Deng C. Magnetism of intermediate hydromaghemite in the transformation of 2-line ferrihydrite into hematite and its paleoenvironmental implications. J Geophys Res. 2008;113:B01103.

65. Ichiyanagi Y, Kimishima Y. Structural, magnetic and thermal characterizations of $\mathrm{Fe}_{2} \mathrm{O}_{3}$ nanoparticle systems. J Therm Anal Calorim. 2002;69:919-23.

66. Cannas C, Concas G, Gatteschi D, Musinu A, Piccaluga G, Sangregorio C. How to tailor maghemite particle size in $\gamma-\mathrm{Fe}_{2} \mathrm{O}_{3}-$ $\mathrm{SiO}_{2}$ nanocomposites. J Mater Chem. 2002;12:3141-6.

67. Tronc E, Chanéac C, Jolivet JP. Structural and magnetic characterization of $\varepsilon-\mathrm{Fe}_{2} \mathrm{O}_{3}$. J Solid State Chem. 1998;139: 93-104.

68. Sartoratto PPC, Caiado KL, Pedroza RC, da Silva SW, Morais PC. The thermal stability of maghemite-silica nanocomposites: an investigation using X-ray diffraction and Raman spectroscopy. J Alloys Compd. 2007;434-435:650-4.

69. Zboril R, Mashlan M, Barcova K, Vujtek M. Thermally induced solid-state syntheses of $\gamma-\mathrm{Fe}_{2} \mathrm{O}_{3}$ nanoparticles and their transformation to $\alpha-\mathrm{Fe}_{2} \mathrm{O}_{3}$ via $\varepsilon-\mathrm{Fe}_{2} \mathrm{O}_{3}$. Hyperfine Interact. 2002; 139(140):597-606.

70. Bukhtiyarova GA, Shuvaeva MA, Bayukov OA, Yakushin SS, Martyanov ON. Facile synthesis of nanosized $\varepsilon-\mathrm{Fe}_{2} \mathrm{O}_{3}$ particles on the silica support. J Nanopart Res. 2011;13:5527-34.

71. Gich M, Roig A, Taboada E, Molins E, Bonafos C, Snoeck E. Stabilization of metastable phases in spatially restricted fields: the case of the $\mathrm{Fe}_{2} \mathrm{O}_{3}$ polymorphs. Faraday Discuss. 2007;136:345-54.

72. Sakurai S, Namai A, Hashimoto K, Ohkoshi S. First observation of phase transformation of all four $\mathrm{Fe}_{2} \mathrm{O}_{3}$ phases $(\gamma \rightarrow \varepsilon \rightarrow \beta \rightarrow \alpha)$. J Am Chem Soc. 2009;131:18299-303. 